\title{
Estrategia de la corona española para la conservación de los presidios menores africanos durante el siglo XVIII (1)
}

Juan Miguel Muñoz Corbalán

Profesor Aỵulante del Departumernto de Arte,

Lniversitat Autònoma de Barcelona

... En otras orasiones se ha tratado de si combendria el abandono de estas plazas, con la miru de excusur los gastos de su manulencirin o de mantenerlos parn evitar ofms prejuicios ...

$(s . f ., 1760)$

BL CONCEPTO TSTRATBGICO DEL NORTE DE AFRICA Y LOS PRESIDIOS METORES

Para la corona española, el afianzamiento de la estructura defensiva y de la seguridad del Estado desde finales del siglo $\mathrm{XV}$ pasaba no sólo por la integridad del territorio peninsular, sino por la consolidación estratégica y militar de sus posesiones fronterizas. Bien en el caso de las Islas Canarias o en el de las Baleares y los reinos italianos subyugados a la Corona de Aragón, la herencia era sensiblemente anterior. Con la llegada al trono imperial de Carlos I, a todos estos territorios se sumaron las provincias flamencas y otros estados centroeuropeos. 
En lo referente al norte de Africa, la reciente relación histórica de los reinos cristianos ibéricos con el mundo árabe convertía esa zona en un estratégico marco para preservar el nuevo Estado unitario organizado por los reyes Fernando e Isabel de cualquier hostigamiento proveniente de Africa. La intención de crear un "glacis de seguridad antelitoral" tras la expulsión de los árabes de la Península Ibérica en la zona del Estrecho de Gibraltar (2), condujo a una serie de intervenciones territoriales. Las razones básicas que movilizaban esta actuación de la Corona tenían un carácter militar, político, religioso y económico; y todo ello se tradujo en la progresiva edificación de torres-vigía costeras, de fortificaciones urbanas y de otras empresas tácticas como la construcción de la base de navíos de guerra en Cádiz. El complemento a esta ambiciosa acción estratégica consistió en la ocupación de pequeñas plazas rifeñas que adquirieron el nombre de presidios, justificando su etimología latina en el sentido de posición militar destacada con un marcado carácter defensivo (3). La conquista de dichos lugares se fue produciendo paulatinamente desde los últimos años del reinado de los Reyes Católicos: Melilla (1497), Sahara occidental (1499), Mazalquivir (1505), Peñón de Vélez de la Comera (1508), Orán (1509)... Con posterioridad se arrebató a los portugueses la plaza de Ceuta (1582), y el resultado general de esta política dominadora hispánica fue el establecimiento de un relativo control sobre los beréberes por tierra y mar (neutralizando en gran medida las hostilidades que éstos habían venido infligiendo con regularidad sobre las costas españolas, l'rancesas, italianas e insulares del Mediterráneo occidental) y la garantización del comercio marítimo y de las comunicaciones entre el Mediterráneo y el Atlántico.

Bajo el reinado de Felipe III se produjo un acontecimiento que nuevamente desestabilizó el orden impuesto por la Corona española en esta parte del Mare Nostrum: la expulsión de los moriscos peninsulares en 1609. Este hecho provocó un aumento de las incursiones que los corsarios beréberes realizaban sobre sus objetivos hispánicos, y, por lo tanto, la consiguiente reacción de la Corona, que, desde el acceso al trono de Carlos I (con todos los conflictos político-religiosos de su reinado) y el aumento del comercio con las Indias, dejó relegado a un segundo término el norte de Africa en favor de Europa y de América.

La decisión Real para contrarrestar el efecto de las nuevas incursiones marítimas rifeñas fue promover inmediatamente la conquista y el 
refuerzo de las plazas costeras africanas más estratégicas. Entre estas intervenciones cabe destacar, durante el reinado de Felipe III, la toma de Larache. Ya gobernando Carlos II se produjo la conquista del Peñón de Alhucemas; $y$ bajo el mandato de Felipe $V$ fueron reconquistadas Orán y Mazalquivir, que habían sido perdidas en 1707, en plena Guerra de Sucesión.

Los logros que se materializaron con esta política ocupadora, tanto la de los monarcas Austrias como la del primer Borbón. consistieron, más que "sugetar provincias enteras en la Berbería", en

deprimir y sugetar los moros con la barrera que havian formado las distintas plazas y castillos que se les quitaban en el Mediterráneo; yugo que poco a poco acabaría (que entonces tenian por mar y tierra) con sus piraterías $y$ comercio marítimo, y hasta con el cultivo de sus campos $y$ poblaciones, en todas las partes o comarcas a que pudiese alcanzar el dominio español (...) (4).

De esta manera, la Corona hispana consideraba haber logrado

establecer una línea defensiva en la costa norteafricana entre los presidios mayores de Ceuta y Orán, pasando por sus lomónimos menores de Melilla. Peñón de Vélez de la Gomera y Alhucemas.

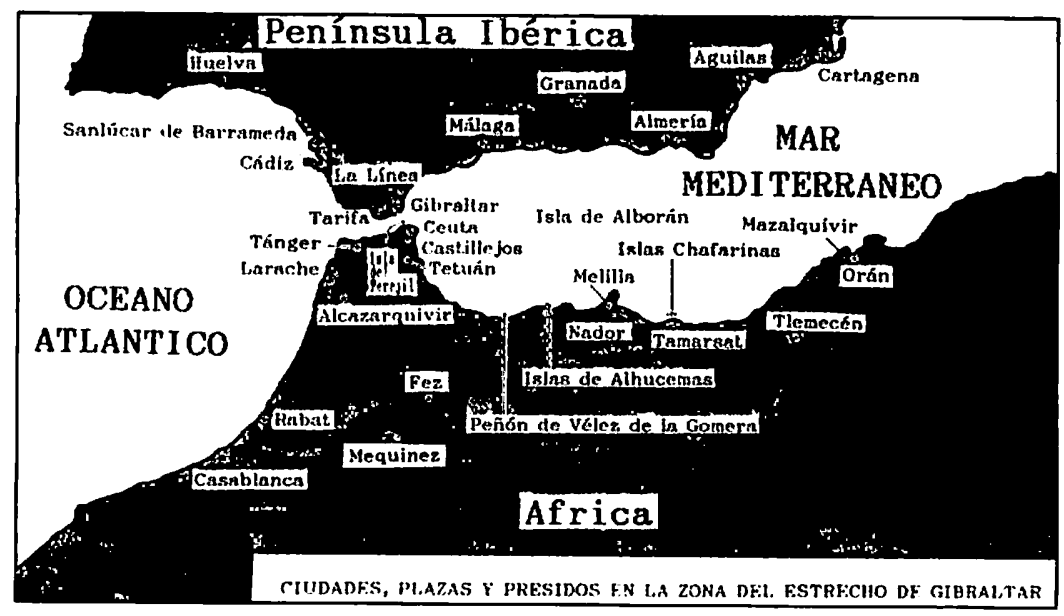




\section{LOS TRES PRESIDIOS MENORDS DEL RIF EN GL SIGLO XVII}

Los tres presidios menores norteal'ricanos, calificados de "cárcel de infelices" por el marqués de la Mina (5), fueron conservados con interés desde el siglo XVI, concurriendo siempre razones de tipo estratégico destinadas a potenciar el dominio hispánico en la zona del Estrecho de Gibraltar.

La preocupación por mejorar el poder defensivo de las tres plazas rifeñas durante el reinado de Felipe $V$ llevó a claborar algunos proyectos de fortificación y a establecer un eficiente sistema de abastecimiento de los tres presidios (6). La simación geográlica de éstos les obligaba a depender directamente de La Capitanía General de Cranada y de la Veeduría de Málaga. Su aislamiento marítimo no ofrecía ninguna ventaja para facilitar el mantenimiento de la guarnición, familiares, desterrados, y de la propia estructura defensiva e infraestructura de supervivencia. En un informe del ingeniero Pedro Coysevox quedaban patentes las incomodidades de todos aquéllos que se hallaban en los presidios:

(...) residen en aquellas plazas mugeres, hixos y hijas, con la forzosa propensión de subministrar alojamientos a estas familias, quando faltan para las propias guarniziones; arlemás que en el Peñón como en las Alhucemas se conduze con crecido gasto el agua de España, consumiendo más una de eslas familias que diez soldados (...), sin la ordinaria de aplicarse un desterrado o dos para serbir dichas familias (...) (7).

A los problemas característicos del espacio habitable y del aprovisionamiento de víveres, se añadía el encarecimiento de todos los géneros, que debían transportarse desde la Península, ya que su carencia en los presidios o la mala calidad de aquéllos hacía indispensable su importación:

(...) En los asientos, el suvido valor de los materiales que se conducen de España para las fortificaciones se deve siempre representar, pues (...) un mínimo reparo llega a ser de entidad, y las obras de algún tamaño no se pueden execular (...) (8). 
Materiales básicos en cualquier obra constructiva como la cal y la madera habían de traerse también (como la piedra y el ladrillo) de la Península, cosa que no resultaba rentable ni conveniente:

\section{(...) También remiten la cal rapagada con agua} del mar; lo que descaeze mucho el probecho y durazión de todas las obras.

El precio de las maderas es más moderado, pero las condiziones mal formadas zitan la sola dimenzión del largo, sin estenderse a los gruesos y calidad en que consiste la durazión (...), y como no tienen los asentistas prebenzión ninguna de madera, embian a cortarla quando se pide, sin alender a la estazión; llega verde, se apolilla en dos años y en tres se necesita de otra, lo que ha dado lugar a tantas chozas, tejados y casas apuntaladas(...) (9).

En lo referente a la edificación de las casas particulares, el descontrol era evidente. En el caso concreto de Melilla. en 1729 podían contabilizarse 75 casas propiedad de la Corona frente a 134 privadas. cuyos dueños en su práctica totalidad "no han hecho conduzir de España todos los materiales a su costa”. Estas irregularidades o apropiación de géneros librados por la Intendencia de Málaga obligaba, al igual que en el resto de España, a seguir rigurosamente la normativa establecida en el Reglamento de Ingenieros de 1718 (10). En el informe de Pedro Coysevox. éste indicaba que

se debe mandar (como se ha representado) que los ingenieros interbengan en todos los materiales destinados a la fortificación; que por la saca de qualquiera dé su zertificazión el ingeniero, espezificando a quién se ha de entregar; por qué obra; y poniendo al pie de ella su orden el Governador y el Ministro su interbenzión (...) (11).

$\Lambda$ pesar de todas estas dificultades, el mantenimiento de los presidios menores no fue cuestionado con rigor hasta el reinado de Fernan- 
do VI, en un ambiente de clara política defensiva por parte de la monarquía tendente a buscar un ahorro en el presupuesto destinado a la Secretaría de la Guerra.

Todavía bajo el gobierno del primer Borbón. las empresas constructivas iniciadas en los tres presidios menores africanos (y en los dos mayores de Ceula y Oráı) fueron sucediéndose una tras otra, una vez satisfechas mínimamente las necesidades defensivas en otras plazas peninsulares conflictivas como Barcelona, indispensables para la configuración del nuevo estado centralista (12).

\section{PEÑON DE VELEZ DE LA GOMPRA (13)}

Este presidio, el más occidental de los tres menores en la costa norteafricana, dependía territorialmente del Reino de Fez, cuyo monarca había visto cómo los españoles se lo arrebataban en 1508. La isla, de una gran aspereza topográlica ("su esterilidad y rudeza es suma porque no tiene fuente, pozo de agua dulze, leña, ni huerta, y lo que es más, ni auı tierra" $[1+])$, resultaba relativamente perjudicial desde el punto de vista de su salubridad (15), aunque, estratégicamente, fácil de mantener su señorío al ser "difícil de tomar por armas, porque es la naturaleza del risco por muchas partes inacesible, y por otras, aunque más lácil, purde disputarse respeto al natural foso de agua de la mar (...)" (16).

Lo escarpado de la isla limitaba la proyección de nuevas fortificaciones:

(...) El Arte ensanchó dos baraderos y suabizó en lo posible la subida a las corlas havilaziones, que son mu. endebles, y lo propio las murallas que abrigan éstas por la parte de los cilados baraderos, hechas únicamente para el fusil, a cuyo efecto tienen dispuestas sus troneras. Las obras de fortificación que tiene son arregladas a la disposición, figura y alineamientos que permilió la naluraleza de la roca, y. assi consiste en una muralla débil que circuye la isla por la parte superior, formando los ángulos y resallos que la peña ofrece, los quales, por admitir alguna capacidad o extensión, tienen el nombre de baluarte, aunque en realidad no merecen el de torreones (...) (17). 
En 1721 era proyectado un fuerte para el Peñón de Vélez de la Gomera, a instancias del Gobernador del presidio Tomás de Castillo y Sagredo y del Veedor del mismo José de Cassaus. El plan de Tomás de Castillo remitía a las ideas propuestus por el Ingeniero en Segundo en la plaza Antonio Contreras y consistía en "construir un fuerte en el Campo de los Moros, no en el paraje del antiguo que se perdió [en el sitio de 1702], sino en la lengua del agua donde fuera comunicado a la plaza, sin que pudieran contrasitiarlo o cortarlo (...)"(18). Las campañas edilicias, según el proyecto. habrían de tener tres fases por lo que respectaba a la fortificación del conjunto: en un primer lugar, la erección de una línea de circunvalación simple a base de fajinas y materiales similares; posteriormente. la fortificación interior de esta línea mediante cl empleo de mampostería de piedra y ladrillo; finalmente, "sería fortificada la plaza con libertad, usando de muchos materiales que ay a la bista $(. .) ".(19)$.

El Ministro de la Guerra contestaba el 6 de mayo sobre la necesidad de que, antes de aprobar el plan, un ingeniero realizara un peritaje en el Peñón. El Gobernador insistía en la conveniencia de la nueva fortificación en el Campo de los Moros, en tierra firme, arguyendo que con dicho fuerte se podrían

mantener las embarcaciones en este frente, como hazian en tiempo del fuerte que se perdió, evitándose lograr demora que aora padezen por falta de puerto, pues luego que entre el viento de poniente se ven precissados a ponerse a la vela muchas vezes (...) y irse a abrigar a las Alhuzemas (...) (20).

Según el Gobernador del presidio, se podría también conseguir aumentar la calidad de vida en el Peñón (mejor salubridad, agua dulce. alimentación...) y la obtención de materiales para sus obras (cal, arena, piedra). lo cual permitiría con comodidad

componer sin riesgo y en toda satisfazión el castillo y passo de la Isteta, tan necessario de reparo como peligrosso y expuesto a perderse por la poca fortaleza que tiene un puesto tan abanzado, $y$ que verdaderamente consiste en él el que esta plaza tenga más o menos seguridad (...) (21). 
Ante la insistencia de los ministros de la Corona en el Peñón de Vélez de la Gomera, el marqués de Castelar dio orden al Ingeniero General. Jorge Próspero Verboom de pasar al presidio y efectuar el reconocimiento a propósito, dentro de una política de hipotético fortalecimiento de los tres presidios menores y, en general, de todas las posesiones españolas en el Rif (22). El Ingeniero General, destinado eventualmente en Málaga para realizar los informes pertinentes sobre obras en el Reino de Granada y su costa. no tardó en expresar su opinión al respecto. En este sentido, el ingeniero flamenco hallaba bastantes dificultades para llevar a buen término la empresa si no se disponía previamente de "un exército para ocupar las mesmas montañas. fortificándolas (...)" (23). Tampoco veía factible Jorge Próspero Verboom "/o de hazer una línea de circumbalación (...) sin ocupar las alturas (...)" (24).

Parece ser que las objeciones interpuestas por el Ingeniero General motivaron ciertas dudas en la Secretaría de la Guerra y el proyecto esbozado por Tomás de Castillo no tuvo continuidad (25).

El Peñón de Vélez de la Gomera, perdido por los españoles el 20 de octubre de 1522, "por estratagema de los moros" (26), y reconquistado el 6 de septiembre de 1564, era considerado diez años después del sencillo informe de Jorge Próspero Verboom como una plaza que permitía. junto a los otros dos presidios menores y a los dos mayores, sugetar

la costa enemiga por la distancia de noventa leguas desde Orán a Ceuta (...), porque sus guarniciones han obligado y perseguido a los infieles hasta arrojarlos de las havitaciones immedialas al mar, sin permitirles existan en los abrigos, ensenadas y calas ni la fábrica de las pequeñas embarcaciones que les servian para el corso de nuestras costas (...) (27).

La supuesta trascendencia del presidio insular había quedado manifiesta en época de Felipe Il con el Reglamento que el rey envió al Alcaide del Peñón en 1575 (28). Siglo y medio más tarde, el criterio al respecto seguía manteniéndose prácticamente igual, aunque con restricciones, ya que no se observaba ningún éxito en lo relativo a uno de los objetivos expresados desde su reconquista (la evangelización de los rifeños), puesto que "ni en el período de doscientos veinte y quatro años se ha extendido por esta parte la religión católica. ni se experimenta que los moros, con el 
deseo de hacerse cristianos, se pasen a la Isla (...)"(29). Tampoco se apreciaban beneficios materiales, "porque ni se aumenta el número de los vasallos ni crece la Real Hacienda, ni se adelanta el comercio (...)" (30).

Desde un punto de vista estratégico, la no existencia de un puerto adecuado en la isla y la necesidad de llevar a cabo numerosas obras "para ponerla en el devido estado de defensa", junto al poco efecto táctico del presidio sobre las tropas beréberes dispersas en la zona continental, menguaban sensiblemente el interés en conservar la plaza. Pese a todo ello. el informe de 1732 reflejaba la utilidad para la Corona del Peñón de Vélez de la Gomera, cuya conservación permitiría mantener libre de corsarios la costa rifeña y. por consiguiente, intacta la navegación y el comercio. En definitiva, la trascendencia para el Estado del comercio marítimo en esta parte del Mediterráneo junto a la seguridad de las costas peninsulares e insulares resultaban ser las dos verdaderas razones para creer que el Peñón de Vélez de la Gomera (como los demás presidios africanos) mantenía su capacidad estratégica, aunque ésta debería ser reforzada:

(...) No basta que estos presidios tengan la fuerza suficiente para resistir a los moros; importa distribuir en ellos una esquadra de embarcaciones de compelente porte para guardacostas y comunicazión entre si y con los puertos de España, que no sólo harían el servicio de perseguir las embarcaciones infieles, sino de evitar muchos cautiverios en nuestra costa, y al mismo tiempo transportar de España quanto necesiten los presidios de Africa. Y no satisface el decir que el rey. mantenga navios, fragatas, javeques, galeotas o qualesquiera especie de guardacostas, porque este servicio lo hará con si exactitud la esquadra propues/a de los presidios, a menos costa y con mayor efecto; porque tripulada la embarcación con gente del presidio, todos son útiles indiferentemente para el cañón (...). No se pretende que los presidios sirvan para internarse en el Africa, dilatando los dominios del rey, ni extendiendo la religión; se procura sólamente quitar a los infieles las utilidades de hacer su corso en nuestras costas y de privarles en todo tiempo intenten una expedición semejante a la invación que hicieron el año 714 (...)" (31). 
En 1774, el ingeniero Juan Cavallero esbozaba el proyecto de reforma de las fortificaciones y de la guarnición del Peñón de Vélez de la Gomera para obtener un mejor balance defensivo del presidio (32).

En vista de los diversos informes y peritajes realizados durante el siglo XVIII, y a pesar de todos los inconvenientes citados. el Peñón se reafirmaba como una de las posesiones hispanas en la costa rifeña de mayor relevancia para la seguridad de la Corona. $A$ su vez. el sitio que el Emperador de Marruecos estableció, sin éxito para él, desde el 3 de febrero al 18 de marzo de 1775, demostró el interés que el monarca rifeño tenía por la posesión del presidio, lo cual contribuyó en buena medida a revalorizar y acrecentar el carácter estratégico del Peñón de Vélez de la Comera.

\section{PEÑON DE ALHUCEMAS (33)}

Esta isla, distante ? leguas al este por mar del Peñón de Véle\% de la Gomera, fue conquistada a los musulmanes por los españoles en 1673, y sus características estratégicas similares a las de aquél hicieron que la Corona hispana mantuviera el interés por su conservación.

El islote de Alhucemas se hallaba provisto de un fondeadero. aunque no del todo seguro en época invernal: y su fortificación. proyectada por un ingeniero francés al servicio de un rico beréber enfrentado a Muley Ismail, había sido concluida en 1668. La escarpada topografía de la isla condicionó, como en el Peñón de Vélez de la Gomera, la estructura defensiva del conjunto.

Las mismas razones que motivaron tomar alguna decisión al respecto de mejorar las fortificaciones del presidio menor más occidental se tuvieron presentes en Alhucemas, por lo que éste no proporcionaba ninguna ventaja complementaria a las ya citadas del Peñón de Vélez de la Gomera:

\section{(...) la circunferencia de esta población es en todo} irregular y determina la peña en que está fundada su configuración, formando varios ángulos entrantes y salientes, sin que aya figura alguna que se aproxime a regular en toda su extensión (...) (34).

En lo relativo a la infraestructura de la guarnición, tampoco la situación era satisfactoria. Entre otras cosas, los cuarteles no estaban 
hechos a prueba de bomba. y para almacenes de víveres estaban habilitados los sótanos abovedados del antiguo castillo. Por todas estas circunstancias, la necesidad de obras de perfeccionamiento fueron constantes desde que la plaza hubo sido tomada en el siglo XVII.

\section{MELILLA}

La característica diferenciadora de este presidio menor (cl más oriental de los tres) con respecto a las del Peñón de Vélez de la Gomera y de Alhucemas radicaba en su ubicación continental. Ello permitió que, desde su conquista en 1497, el recinto fortificado inicial pudiera expandirse espacialmente (provocado por una necesidad de aumentar la capacidad defensiva de la plaza), dando lugar hasta tres nuevas áreas amuralladas realizadas entre los siglos XVI y XVIII (35).

En 1722 se realizó el primer informe amplio del siglo XVIII sobre Melilla, sus fortificaciones y la provincia de Alcalaya (36). El peritaje técnico se limitaba a una narración histórica y a la descripción del estado de la plaza, sin emitir juicios de valor sobre la capacidad estratégica del presidio. Jorge Próspero Verboom había claborado un plan de mejora de las fortificaciones melillenses, haciendo especial énfasis en "la montagne nommée du Cubo et de la Cantera qui domine toute la place (...)" (37).

Precisamente sobre el Cubo de Velilla, debido al interés en fortificar esa zona, la Secretaría de la Cinerra encargó un detallado memorial destinado a aumentar la capacidad defensiva de la plaza por ese lado, de evidente trascendencia estratégica para su seguridad:

\section{(...) El dicho terreno, o altura del Cubo, es de un} grande perjuizio a la plaza por estar elebada más que el plano de sus fortificaciones diez y seis tuessas, de lo que se origina estar todas sus obras irregulares y sin la lexítima defensa, pues carece totalmente de la del fusil por estar tan elevados sus parapelos a fin de cuvrirse de la dicha altura (...) (3S).

Este proyecto de fuerte presentado por el ingeniero Juan de Laferriere en 1728 para ser ubicado en el Cubo no se pudo realizar a corto plazo, a pesar de que el plan estaba ampliamente detallado y repasado por el propio Ingeniero General: 
(...) se dispondrá luego trazar la estrada encuvierta del fuerte proyectado, formando su parapeto con zestones, $y$ inmediatamente plantar su estacada. Al mismo tiempo se formará un parapeto a una tuesa interior de la traza de la escarpa del fuerte, en la forma que lo previene el Exmo. Señor Marqués de Verbom en su Insliuzión, delante el qual se pondrán los cavallos de frisa, y después se hechará mano luego a la escabazión del foso de dicho fuerte, valiéndose de las tierras que de él se sacaren para formar el glasis, las quales se deverán transportar de noche a la parte que mira a la pequeña Rambla. También no se perderá un instante en executar la comunicación que deve ir desde la estrada encubierta del ángulo de Santiago al menzionado fuerte. En ínterin que se forma su gola de mampostería se zerrará de una estacada (...) (39).

El acoso de los beréberes por esa parte de Melilla se venía realizando de forma insistente, según su Gobernador, desde 1694. El 12 de julio de 1729, mediante una acción dirigida por el ingeniero Juan Martín Zermeño, aquéllos fueron desalojados provisionalmente de sus posiciones (40). Esta operación fue realizada aprovechando las luchas intestinas entre facciones de los árabes de $\mathrm{Fez}$, lo que alivió momentáneamente el transcurso de las obras constructivas. Juan Martín Zermeño indicaba que

los moros de este campo son pocos y temerosos de que los christianos no les bayan a dar algún Santiago. Duermen a las puertas de sus cassas y están tan deseosos como esta guarnición de que se fortifique el Cubo, pues con esto dizen se atacarán distantes de la plaza, a impedir sólo el que no se les baya a inquietar (...) (41).

A pesar de acciones de los españoles como la expresada, el hostigamiento de los beréberes por la parte del Cubo volvió a ser importante al cabo de poco tiempo (42).

El proyecto de fuerte en el Cubo seguía teniendo dificultades para su realización, aunque Juan Martín Zermeño, con su labor continuada en la dirección de las obras, intentaba acelerar su erección: 


\section{(...) Ia del plano y perfil (del fuerte) no a podido} hasta aora tener efecto, aunque to he intentado varias bezes, porque an acudido los moros a impedirlo y me he retirado por no acreditar la sospecha ni empeñar nuestra gente. Lo repetiré siempre que la ocasión lo permila hasta lograr la que deseo, y. pasarla a mano de V. E. (...) (43).

Los toques de attención sobre la trascendencia de acelerar el ritmo de las obras se fueron sucediendo, proponiendo incluso modificar el proyecto original de Juan de Laferriere para abaratar costes:

\section{(...) siempre que los enemigos pongan en aquel} paraxe (del Cubo) una bateria reduzirá a zeniza todas estas fortificaciones, y haciendo reflexión de que tal vez tendrá suspensa esta deliberación la máquina de gastos que contienen los proyectos que hizo el ingeniero Don Juan de la Ferriere, no puedo dejar de dezir a V. E. que, para asegurar el dominio de esta allura y evitar el que los sitios de los moros puedan acercarse y. hacer mucha operación, basta un fiuerte reducido, siempre que se consiruya sobre la allura del nombrado Cubo (...) (44).

Las obras continuaban su curso con las dificultades propias debidas al acoso de los musulmanes y a los retrasos del transporte de materiales provenientes de Málaga. Por otra parte, la fortilicación del Cubo necesitaba, según Pedro Coysevox, integrarse en una empresa más amplia que asegurase todo el flanco oeste del presidio y otras partes del recinto fortificado:

\section{(...) no contiene hazer la referida fortificación del} Cubo sin haver acarado la recomposición del Fuerte de San Miguel, por el auxilio que puede dary tener esta parte segura. y considero aún más seguro lo siguiente.

Acavar las cinco bóvedas que fallan a la cortina de San Fernando; fabricar a los treinla y ocho merlones que hay en las obras nuebas exteriores; sus banquetas para usar el fusil en sus parapetos; acavar la contraescarpa, como el fosso del más adelantado fuerte. 
Reparar la obra del Fuerte de San Antonio, arruinado por el combate del mar, siendo la defensa del parage donde ancoran las embarcaciones.

Construir el baluarte proyechado a la izquierda de Santiago, delante el Torreón del Vehedor, siendo obra que determinó el Marqués de Verbom quando estumo en ella.

Fabricar un horno a prueva de bomba en el Huerto del Hospital.

Anchar el terraplén de la Concepción hasta los quarteles de los soldados, a fin de manejar al pie del macho quatro piezas de artillería que tiren sobre el Cubo.

Acavar de cubrir quarteles que se está en Alberca, junto a la iglesia, pues la fortificación del Cubo es reservada para la perfección y tolal quietud de la plaza; pero es general propensión de todos los presidios adelantarse siempre, sin tener en estado ni acavar lo de atrús (...) (45).

Esta última frase del Coronel de Ingenieros acerca de la falta de conclusión y perfeccionamiento de las obras de fortificación en los presidios es muy significativa. En el caso de Melilla, el sentido de provisionalidad en el resultado de las empresas constructivas era más patente que en los otros dos presidios menores: debido al cómodo hostigamiento beréber por tierra firme. Durante los últimos años del reinado de Felipe $V$ y el mandato de Fernando VI, las obras en esta plaza se fueron realizando según el curso habitual expresado por Pedro Coysevox. Pero es ya durante el gobierno de Fernando VI cuando comienzan a plantearse seriamente ciertas dudas acerca de la conveniencia o no de mantener bajo la soberanía hispana Melilla y los demás presidios rifeños.

\section{REFLGXIONES SOBRE LA CONSERVACION O II ABANDONO DI LOS PRESIDIOS MENORES}

La sensación experimentada en la Secretaría de la Guerra sobre el escaso pragmatismo que suponía conservar los presidios menores de la costa norteafricana y efectuar un continuo derroche de medios económicos para tener mínimamente operativo el carácter defensivo de sus fortificaciones frente a los beréberes, indujo a la Corona a plantearse la posibili- 
dad de renunciar a dichas posesiones. En 1746, las guarniciones ordinarias de los presidios de Melilla y Peñón de Vélez de la Comera fueron reducidas a la mitad (46). Dos años y medio después del fallecimiento de Felipe V, el 26 de diciembre de 1748. el ingeniero Juan Martín Zermeño (ya ascendido meritoriamente a Cuartel Maestre General) recibía el encargo de elaborar un informe relativo a dicha cuestión. La solicitud se había producido "teniendo el rey presente los grandes dispendios que ocasionan los cinco presidios que tiene en la costa de Africa, con poca utilidad del Estado"; por lo cual el monarca observaba su deseo de "administrarlos con el abandono de los inútiles y reducción de las fortificaciones en los otros (...) (47). El memorial, siguiendo las instrucciones del Ministro de la Guerra, se refería a los cinco presidios. Por lo que respecta a Ceuta, no dudaba de su conservación. Sobre Orán, al no conocer la plaza y sus características, no se pronunciaba definitivamente. Acerca de los tres presidios menores. Juan Martín Zermeño centraba también su análisis en la utilidad de dichas plazas, siempre en unos términos bastante moderados. He aquí un cuadro aclarador con las opiniones del ingeniero:

Presilio

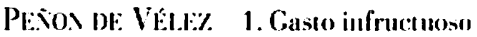

DF I.A GOMIERI

para In Real I lacienda

2. Necesidad de trurr de

la Península

municiones, agua,

pertrectos. viveres.

materinles de construccion..

3. Carencia de fomdendero

a cubierto

4. Horror de la guaruición

a cste destino
A rivol

1. Pueven natural ide hucha profuncliclad

2. Posilsiliclad de: comtrolar y elimimar los corsarios beríleres

3. Ahorro de guardacostas alternativos

Opision

Conservación. pero

necesidad de reparar

las forlificaciones

Al.HI CI:HIAS

1. Impide el uso de la bahía

Conservación por los musulmanes

2. Buen fondeadero

con alsrigo 
Miı.II.I.I

$$
\begin{aligned}
& \text { 1. Ausencia de puerto } \\
& \text { y bahía } \\
& \text { 2. Considerable gasto } \\
& \text { de mamtenimiento }
\end{aligned}
$$
1. I.ugar de adiestramiento Tendencia de la rropa al abandomo

Juan Martín Zermeño no se pronunciaba abiertamente sobre la renuncia a Melilla, aunque no observaba ninguna razón que indujera a su conservación, añadiendo que, "aunque se abandone, no deben recelarse de aquella plaỵa tan grandes perjuicios sobre nuestras costas (...)" (48).

Tras este informe del Ingeniero Director: la Corona recibió el análisis técnico de Antonio Gaver, también ingeniero y Director de la Academia de Matemáticas de Orán desde 1736, a la vez que experto en obras en la región. El memorial de Antonio Gaver reproducía prácticamente las opiniones de su colega Juan Martín Zermeño, aunque matizaba algunos datos. En definitiva, se decantaba por la conservación del Peñón de Vélez de la Gomera. "reduciéndose sus fortificaciones", y de Alhucemas (como de Orán, Mazalquivir y Ceuta), mientras que veía claro el abandono y la demolición de Melilla (49). En el siguiente cuadro quedan sintetizadas las opiniones de Antonio Gaver:
Phesine)
EN contm
A IAvon
OPINION

PENOX DI: VELEZ 1. Exesivos gastos
DE LA GOMIRA

AlHowns

$$
\begin{aligned}
& \text { 1. Puerto poro seguro } \\
& \text { yescasumente úil } \\
& \text { 2. Vecindad de los } \\
& \text { demás presidios }
\end{aligned}
$$

Whi.IIII

1. Impide el abrigo de los corsarios musulmantes

1. Lispaciosa ensenada hábil como puerto y abrigo Intural

Antonio Gaver añadía una proposición sobre la constitución de un potente corso español operativo en los puertos de los presidios rifeños, lo 
cual permitiría, como ya hicieron los ingleses ante la polémica de conservar Tánger o Gibraltar, deshacerse de un presidio menor más y ahorrar los gastos relativos a su mantenimiento:

\section{(...) si fuere del agrado de S. M. permitir armas-} sen en corso algunos de los vasallos que lo han propuesto, destinándoles para puertos determinados a igual número de ellos Zeuta, Orán y Alhuzemas (quedando a la Dirección del Tribunal que corresponde el modo de impedir los contrabandos), no sólo servirian al fin referido, sino también de socorrer y assistir a la manutención de estas plazas a muy poca cosia del Real Herario, y aun quizás mejorando la idea supuesta, se podría tal vez abandonar uno de los dos Peñón o Alhuzemas, graduando el de mayores ventajas, a imilación de Inglaterra, que aun consideraba a Tánger de iguales circunsiancias a las de Gibraltar, le abandonaron y demolieron en 1654 por los crecidos gastos que les ocasionaba (...) (50).

A raiz de estos informes solicitados a los prestigiosos ingenieros militares, la Corona resolvió proclamar una nueva planta relativa a la guarnición de los presidios. Debido al carácter excesivo del gasto que su mantenimiento representaba para la Real Hacienda. esta nueva planta ordenaba una reducción de dichas guarniciones.

Durante todo el reinado de Fernando VI, el proceso relativo a la polémica de los presidios parece haber estado congelado (no hay constancia de ningún otro informe al respecto), y sólo dos años antes de su fallecimiento se establecía un reglamento para confeccionar una nueva planta y gobierno de los tres presidios menores. La desaparición de Fernando VI coincidía con el resurgimiento de la controversia sobre el futuro de las plazas rileñas.

En la sucesión al trono, la Junta de Cenerales bajo el mando del Ministro de la Guerra, Ricardo Wall, recibía otro breve informe acerca de lo que pocos años más tarde sería calificado como "expediente controvertido de mucho tiempo a esta parte" (51). En la citada relación anónima se hacía mención a los dictámenes pedidos "a algunos generales experimentados", refiriéndose claramente a Juan Martín Zermeño y a Antonio Gaver. 
Sin embargo, el tono general de este pequeño análisis era ciertamente conservacionista en su integridad. De Melilla decía que, "aunque no tiene puerto ni abrigo, ni a primera vista ofrese ventajas, si estubiese en poder de los moros, les facilitaría sus incursiones desde ella (...)". Del Peñón de Vélez de la Gomera, el autor opinaba de una manera similar: y con respecto a Alhucemas, defendía las características naturales de su fondeadero:

(...) si dichas plazas dejasen de subsistir en oposición de los berberiscos, pudiendo valerse éstos de sus inmediaciones, tendrían más continuadamente infestados aquellos mares, $y$ cayendo repentinamente sobre nuestras costas harian más freqüentes incursiones en ellas con gravissimos daños e inquietudes de los pueblos pequeños, que no sería fácil de evitar sino a expensas de muchos guardacostas y augmelo de guarniciones que ocasionarian mayor dispendio que el que motivan estos tres presidios (...) (52).

La ambigïedad resolutiva de este texto, carente de un análisis profundo de las circunstancias particulares de cada presidio, evidencia la indecisión de la Corona ante la polémica que se venía arrastrando varios años. Todavía bajo el ministerio de Ricardo Wall, la Real Orden del 23 de julio de 1763 dictaminaba sobre la inminencia de hacer "un prolixo reconocimiento por un oficial de conocida inteligencia, dos ingenieros y el Capitán de Navío que por la vía reservada de Marina se destine a este efecto" para emitir, 'como final examen', un juicio definitivo sobre conserbar o demoler los tres presidios menores (...)" (53). Los cuatro peritos nominados para llevar a cabo esta empresa fueron Felipe Cavallero, Teniente de Rey en Cartagena e Ingeniero Extraordinario desde 1741; Mateo Vodopich, Coronel de Ingenieros; Segismundo Font, Teniente Coronel de Ingenieros; y el Capitán de Navío Pedro Justiniani. Las instrucciones pertinentes ya habían sido redactadas previamente a la promulgación oficial de la Real Orden. Concretamente, Mateo Vodopich y Segismundo Font tenían ya confeccionada su labor a realizar en Melilla. Peñón de Vélez de la Gomera y Alhucemas (54).

Las observaciones de los cuatro expertos quedarían estructuradas en ocho puntos que, a su vez, conformarían la elaboración de los memoriales: 
1. Descripción "clara e individual" de la situación del presidio, sus fortificaciones exteriores c interiores, y edificios militares y civiles; realizada tras una minuciosa visita sobre el terreno y acompanada de "un plano justificado dispuesto a escala comprensible para la mejor inteligencia de todo".

2. Relación detallada del número y del calibre de la artillería existente en el presidio y del estado de utilización y conservación.

3. Presupuesto del gasto que supondría el mantenimiento del presidio, sus fortificaciones y artillería durante un periodo determinado (realizado normalmente por quinquenios).

4. Descripción física de la costa rifeña próxima (haciendo especial énfasis en las calas y abrigos donde pudieren refugiarse los musulmanes), con el detalle de los núcleos de población, cultivos, etc..

5. Narración histórica militar de la conquista, sitios, etc., del presidio $y$ de las obras de fortificación realizadas desde su conquista.

6. Dictamen sobre la conservación o el abandono del presidio.

7. En caso de juzgar conveniente el abandono, proposición de " los medios que considere más propios para ponerlo en práctica así en quanto a la demolición de las fortificaciones como para cegar e inutilizar su pequeño puerto".

8. En caso de conservación, indicación del proyecto para mejorar sus fortificaciones y la defensa artillera, con expresión detallada del presupuesto económico.

El resultado de esta Instrucción lo constituyó el extenso informe firmado por Mateo Vodopich (55). La distribución de funciones quedaba de la siguiente manera: Mateo Vodopich, ayudado por Segismundo Font. para el peritaje de las fortificaciones y de la artillería: Pedro Justiniani. para lo relativo a las costas; y Felipe Cavallero, encargado de la visión histórica de cada presidio y de la coordinación general de todos los participantes, centrando especialmente la atención en lo relativo al posible abandono de las plazas, principalemente "sobre la importancia de inutilizar con las ruinas aquellos sitios y cegar sus puertos, calas y abrigos, de modo que nunca puedan tenerlo allí los moros para ofender nuestra navegación, comercio y costas (...)"(56).

La empresa se inició el 22 de agosto de 1763 al embarcar los comisionados hacia sus destinos en la costa norteafricana. El 6 de septiem- 
bre comenzaron su trabajo en Alhucemas: el 15 en el Peñón de Vélez de la Gomera; y el 28 en Melilla. Su regreso se produjo el 3 de noviembre, e inmediatamente llegaron a la conclusión conjunta de que "no se halla razón alguna de moral christiana, política ni militar que persuada a la conservación de estos presidios, ni que pueda ser conveniente ésta a la Religión ni al Estado (...)" (57). Las ideas se resumían en cuatro puntos básicos: el mantenimiento de los presidios se había venido realizando hasta la fecha de una manera rutinaria, si bien en un principio la razón principal de esa actitud estaba condicionada a las incursiones de los corsarios beréberes y turcos en la Península lbérica: la poca efectividad del intento de "convertir" al cristianismo a los musulmanes; el escaso interés estratégico de los presidios: y. en el caso de mantenerlos, la necesidad imperiosa de invertir en ellos una gran cantidad de caudales para poder instalar una buena guarnición y dejarlos en eficaz estado de defensa. Felipe Cavallero, en su resumen de las conclusiones generales, daba las razones de por qué los tres presidios no eran convenientes al Estado: comercio, ni siendo posible sirvan de freno estos presidios a los moros para contener sus incursiones y correrías en las costas de España, no se sigue en mantenerlas utilidad alguna; amles bien, en su conservación se les presentan frequentes ocasiones de presas con las muchas embarcaciones que, desde Málaga, es precisso pasen a ellos para las mudas de tropa, condución de biberes, otros efectos y gente que por castigo se conduce a aquellos parages (...); pues, teniendo con la proximidad a Tetuán la facilidad de emplear a este fin las galeotas necessarias y la de poder ocultarlas de noche sin ser vistas en las varias calas que hay en ella y hallarán más a propósito para el intento, lograrian sin duda pressas seguras continuamente, saliendo al enquentro a los barcos que van y vienen a carla uno de ellos (...)" (58).

He aquí un cuadro donde quedan sintetizadas las objecciones de los expertos hacia la conservación de cada uno de los presidios: 
Presilolos

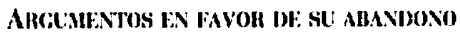

PEX̃oN DE: VÉl.E\% 1. No perjudica a los beríberes ni por mar ni por tierra

DE I G GOMERA 2. lil estado del presidio no permite evitar el corso de los musulmantes

3. Si se ahandona. se evita el apresamiento de las cmbareaciones de abastecimieno provenientes de la Península

4. Se crvita la deserción y la relnjación de costumbres por parte de la guarnición

5. Cegando el puerto y demoliendo las fortificaciones los bereberes no pueden resundar su corso

Al.h CENas 1. No perjudica a los beréberes ni por mar ni por lierra

2. La artillería del presidio no domimn toda la lmhía

3. 1 a amplitud de la bahía hace quee, coll caso de ahandono. pueda soguirse utilizando sin riesgo

4. Mejor invertir en una urmada pue en un presidio

5. Xo conviene hacer una umpliación de su purro

6. Fa caso de abandono de los presidios. el purro pierde su utilidad inicial de servir de albrigo en la resenla de las combarcaciones

ME:III.IA 1. No perjudica a los bercheres ni por mar ni por tierra

2. En caso de abandono, les musulmunes no pordrín volver a utilizarlo como foco de su corso

3. Se evita la deserción

4. Más importame controlar la costa peninsular yur normefricana (urejor mantener una esoutadra naval)

5. Excesivo grastu de mantenimiento

El informe proporcionado por los cuatro peritos daba detalles de cómo realizar el desmantclamiento de los presidios y lograr así su completa inutilización en caso de que los beréberes se hicieran con ellos. Los datos dependían de las características particulares de cada plaza, aunque existían unas ideas comunes, como que todo "deberá executarse con la menor bulla o mayor silencio posible, por el riesgo que puede tener para la consecuzión del todo el que los enemigos observen la diminución de fuerzas" (59). En general, las labores consistirían en la inutilización de sus puertos y la demolición de las fortificaciones y demás edificios interiores. El personal encargado de realizar dichos trabajos serian "minadores, maestros oficiales referidos que deben ir, tropa y presidiarios (...), a quienes se les podrá ofrecer su indulto, y a aquéllos alguna gratificación (...)" (60). la evacuación comenzaría por "el embarco de familias y artillería y sus efec- 
tos, según vea la mayor o menor urgencia de ellos el oficial director de toda la obra (...)" 61). En el caso de Melilla.

se demolerá el recinto y casas a pico y palanqueta, arrojando todas las ruinas de el frente al sur, en el fondeadero (de que tal vez convendrá minar según la acción que intentasse el moro, como assimismo todas las obras accesorias), para excusar el excesivo gasto de pólbora y execución de hornillos (...). Al mismo tiempo, los minadores trabajarán las minas o hornillos en los fuertes y reductos, Victoria Nueva y Vieja, San Miguel, Baluarte de San Joseph el Baxo, Luneta de Santa Isabel, Torre de Santa Bárbara y espigón, haciendo barrenos en la cerca de la huerta y comunicaciones con los fuertes abanzados (...) (62).

Finalmente, los trabajadores irían abandonando los presidios según fueran concluyendo su labor, "dexando para la última retirada los más precisos solamente para dar fuego, con el Governador, a cuyo cargo está la plaza; Beedor, para la qüenta y razón: y el director de la obra" (63).

Según el informe pericial, la suma total de los gastos de demolición, abandono y evacuación de los tres presidios ascendería a 463.790 reales 30 maravedis de vellón, de los que podrían descontarse 203.806 reales 6 maravedís en el caso de que el flete de las embarcaciones necesarias para transportar personas, enseres, pertrechos, etc., se efectuara con naves de la Corona (64.)

Todo este informe redactado por Felipe Cavallero, Mateo Vodopich, Segismundo Font y Pedro Justiniani había sido realizado teniendo en cuenta el asesoramiento del Veedor de Málaga Miguel de Monsalve, a quien con misma fecha de 23 de julio de 1763 la Secretaría de la Guerra le había encargado un memorial en términos económicos (65), El análisis de Miguel de Monsalve quedaba enfrentado directamente a las opiniones de los cuatro peritos. El veedor se decantaba por la conservación de los tres presidios atendiendo a las ventajas que, según él, éstos proporcionaban a la Corona: posiblidad de asegurar el éxito en una hipotética guerra contra los musulmanes: garantización de la seguridad de las costas españolas: y mantenimiento y potenciación del comercio en el Mediterráneo (66). De nuevo 
eran esgrimidas, pues, las razones que habían imperado desde los tiempos de los Reyes Católicos en lo relativo a las plazas rifeñas.

Los argumentos conservacionistas de Miguel de Monsalve, apoyado por el Veedor del Peñón de Vélez de la Gomera, Martín de Córdoba (67). giraban en torno a evitar el "comercio pasivo" al cual había venido estando sometida la Corona hispana debido al efecto del corso musulmán en el Mediterráneo occidental (68). Por otro lado, el mantenimiento del status quo en el Rif por parte de la Corona española traería. según su criterio, dos consecuencias indirectas positivas: imposibilitar al Rey de Marruecos el acceso a un puerto en la costa norteafricana desde donde organizar una armada y un corso efectivos; $y$ favorecer la continuidad de los privilegios que poseían los beréberes "fronterizos", relativamente interesados en la presencia hispana, ya que de esta forma podían mantenerse libres de la contribución a su monarca:

\section{(...) Los moros que havitan distantes aunque sea} 12 ó más leguas a levante, poniente o mediodía de nuestros presidios menores han sido exceptuados por algunos reyes de Fez de las garrama o contribuciones Reales, con pretextos de que acudan a los rebatos de la costa, mantengan guardias en los ataques y puestos que miran a dichos presidios, y de que les hagan continua guerra; $y$ han adquirido tanto derecho de esta excepción que si algún otro rey ha querido privarlos de ella se han defendido obstinadamente (...). Pero si por suerte se abandonaren dichos presidios, vendría todo al contrario: ni lograrian los naturales la exempción, ni tendrían motivo para la excusa (...) (69).

El Veedor de Málaga apoyaba, además, una política española más expansionista en el norte de Africa, a pesar de los crecidos gastos que ello supondría para la Real Hacienda, como era el caso de Inglaterra respecto de Gibraltar:

(...) los ingleses saben muy bien, y lo han publicado en sus memorias, los inmensos gastos que causa a aquella nación la subsistencia de la plaza y presidio de Gibraltar; 
pero no obstante apoyan los más háviles politicos por infinitamente más interesante el daño que con él nos hacen que el ahorro de dichos gastos, como se ha visto en la última guerra; $y$ no heran necesarios estos exemplares (...) para exforzar la comparación de nuestros presidios africanos. Los moros sentirán eternamente el yugo de ellos mientras subsistan, y assí. conociendo el mal que les ocasionan, han tentado en muchas ocasiones atacarlos con obstinados y largos sitios (...), pues experimentan que no pueden vivir en reposo, ni lograr la felicidad de sus terrenos hasta que nos auyenten de ellos; $y$ asi se nota que para destruirlos más no nos contentábamos con quitarles sólamente los puertos, sino también algo más como Tremecén, Orán y otros pueblos (...) (70).

La divergencia de criterios entre lo expresado por Miguel de Monsalve y por los cuatro peritos, encabezados por Felipe Cavallero, creó una mayor incertidumbre en la Secretaría de la Guerra, ya que ambos memoriales ofrecían sólidas razones que defendían, respectivamente, dos opiniones contrapuestas.

Ante esta situación, medio año más tarde del dossier de Felipe Cavallero, Mateo Vodopich, Segismundo Font y Pedro Justiniani era promulgada una Real Orden el 17 de julio de 1764 que reconocía "no ha sido suficiente a la desición la dilixencia de los quatro oficiales, respecto de haberse señido a reflecciones limitadas y circunscriptas (...)" (71). Esta inquietud dio pie a solicitar un nuevo informe a una persona que había servido "algunos años" en los presidios menores (72) Los términos de este memorial son idénticos a los que el ingeniero Antonio Gaver había manifestado en 1749, por lo que, junto a su biografía profesional, puede suponerse correcta la atribución de su autoría. Los argumentos básicos para iniciar la reflexión eran claros:

El azumpto de fortalezas para la conservación de un Eslado es gravissimo, por las muchas circunstancias a que deve atenderse para conseguir el fin de la seguridad, tranquilidad y prosperidad que por derecho natural y siluación se deben proporcionar a las fuerzas del Estado; porque si no 
puede substenerlas, contribuyen a su ruina más que a su provecho (...) (73).

El informe de este personaje analizaba las dos opiniones enfrentadas, intentando hallar un criterio lógico para el devenir de los presidios menores; ideas que se aproximaban esencialmente a las defendidas por los veedores de Málaga y del Peñón de Vélez de la Gomera, haciendo una explícita apología de sus opiniones (74). Los puntos básicos de estas Reflexiones quedaban así:

1. Ltilidad al Religión y al Estado, puesto que "importa a la pureza de la Religión alexar del corazón del reino a los escandalosos, iniquos y relaxados, que reciviéndose allí con las notas de sus condenas no causan daño alguno, y en España le ocasionaría grande, infestando con el mal exemplo a los vuenos (...)". Es la visión del destierro como un "castigo medicinal" (75).

2. La deserción de los presidiarios y las presas de los moros se producirían únicamente por la falta de medios a raíz de la nueva planta de 1746 (76). Por otro lado, las mejores lacilidades de diversión en Málaga hacían que las deserciones se produjeran allí en mayor número que en los presidios (77).

3. Si se abandonaran los presidios, los musulmanes los habilitarían para su provecho ( $y$ toda la costa rifeña) (78).

4. Rentabilidad de aplicar caudales para organizar una pequeña flota defensiva en los presidios y para realizar las obras de fortificación necesarias (79).

Estos puntos aparecen desarrollados en un documento anexo en el que su autor hacía especial énfasis en iniciar el discurso con la idea de que

la frontera de España correspondiente al mediodía merece particular atención, porque las costas de Andalucía, Granada, Murcia, Valencia y Cathaluña son las más apreciables por su fertilidad y comercio del Mediterráneo, $y$ principalmente por tener a la distancia de 3,5 leguas la costa 
de Africa, cuyos bárbaros enemigos del nombre christiano lo serán eternamente de nosotros (...) (80).

En definitiva, con estos informes el peritaje realizado por Felipe Cavallero, Mateo Vodopich. Segismundo Font y Pedro Justiniani quedaba prácticamente anulado, y, en teoría, a partir de esc momento las iniciativas en los presidios menores habrían de considerar su mantenimiento y refuerzo. Un plan propuesto por el conde de Aguilar en 1731 volvió a tener cierta resonancia. El proyecto trataba de emplear las cuatro órdenes militares españolas (Santiago, Calatrava, Alcántara y Montesa) en los presidios y cumplir de esta manera los objetivos para los cuales dichas órdenes habían sido instituidas (81). Según el citado plan, se conseguirían una serie de objetivos:

1. Un "servicio grande al Papa y a todos los Príncipes christianos limpiando de corsarios, moros y piratas las costas de Italia, Venecia, Nápoles, Malta, Sicilia, España y Portugal" (82).

2. Garantización de "la libre navegación del Mediterráneo". asegurándola mediente la formación de una escuadra, "mejor que con la multitud de torres" (83).

3. "La Nobleza en particular se utiliza en dar buena crianza a la juventud" (84).

Esta propuesta, sin embargo, no tuvo trascendencia. El problema prioritario era la resolución de la polémica sobre la conservación o el abandono de los presidios. El Ministerio de la Guerra se veía obligado, pues, a recabar mayor información de manos de prestigiosos personajes que conocieran con detalle el tema de la estrategia militar aplicada al mantenimiento de las plazas fuertes, y que, a ser posible, hubieran estado activos en esos destinos. En esta ocasión le tocó el turno a los ingenieros Pedro Lucuze, Director de la Academia de Matemáticas de Barcelona, y a Pedro Martín Zermeño, hijo de Juan Martín e Ingeniero Director del Principado de Cataluña, quienes, a instancias del Capitán General de Cataluña, marqués de la Mina, confeccionaron el pertinente memorial (85). El informe conjunto seguía el esquema de los realizados a raíz de la Real Orden del 27 de julio de 1764. Básicamente, el análisis de ambos estaba dividido en tres partes: 
1. Razones generales y particulares para electuar el abandono y la demolición de los presidios (86).

2. Importancia de su conservación y restablecimiento de su estado anterior a $1746(87)$.

3. Reflexiones políticas y militares sobre la cuestión (88).

Los argumentos, segín los autores, serían fieles a la importancia estratégica de los presidios, "y sin perder de vista las mejores máximas de política, economía, religión y arte militar que conducen a la felicidad del Estado (...)" (89), y en su intención no estaba

hacer crítica de quanto se expone por uno y otro partido, sino decir sencillamente lo que nos parece conducente a formar el dictamen, apoyándole en aquellas máximas que se conforman y dirigen al vien del Estado con arreglo a convinar las ventajas y los tiempos (90).

Sus opiniones personales se estructuraban en siete cuestiones básicas:

1. "Sobre la naturaleza de los Presidios".

2. "Motibos que en lo antiguo se tubieron para la conquista de estas plazas y los de su conservación".

3. "Razones que persuaden la conservación de los tres Presidios menores".

4. "Sobre inutilizar los puertos y demoler las plazas".

5. "Sobre las ventajas positivas o negativas que en el día no se reconocen".

6. "Sobre el equivalente al gasto de los 3 Presidios menores".

7. "Sobre algunas consideraciones importantes".

Es muy interesante la reflexión previa que Pedro Lucuze y Pedro Martín Zermeño hacían sobre las características intrínsecas de las plazas de guerra. estableciendo las diferencias esencial entre las plazas "necesarias" y las plazas "útiles" o "provechosas": 
(...) las plazas de guerra necesarias a la conservación del Eslado regularmente se situan en las fronteras, sobre forzosas avenidas o para cubrir alguna parte de pais abierto, y quanto más pequeñas (si por ellas se logra el fin) son menos costosas al Real Herario. Las úliles o provechosas se colocan en lo interior del reino por otros respectos, cuya explicación no conduce al intento, ni menos el múmero, magnitud ni figura. Pero importa advertir, según la mejor politica y economia, que el Estado no deve empeñarse en mantener más fortalezas que aquéllas precisas a su conservación, con proporción a las fuerzas del reino y a las que tienen o pueden tener los principes confinantes según sus intereses particulares (91).

La especificidad de los presidios africanos (como tales, avanzados estratégicamente respecto del territorio peninsular) los incluía entre las plazas necesarias. Pedro Lucuze y Pedro Martín Zermeño argiuían que esta situación "exterior" permitía tener alejado al enemigo, cubrir las costas peninsulares y contribuir al dominio del Mediterránco occidental próximo al Estrecho de Gibraltar. Estas facultades se veían favorecidas por la ubicación de dichos presidios, de manera que cada uno de ellos cubría una distancia en la línea de costa más o menos semejante, de unas 16 leguas de media (92).

Tanto el Peñón de Vélez de la Gomera como Alhucemas cran dificiles de asediar por mar. Alhucemas era también inexpugnable por tierra. Respecto de Melilla, ambos ingenieros observaban que esta plaza

\section{(...) tiene la excelencia de no ser dominada inme-} diatamente, y que sus frentes son libres de ataques, a excepción del que une a la plaza con la tierra firme: pero como está bien fortificado y es el único objeto de la guarnición, con facilidad se defiende (...) (93).

De este modo, los tres presidios menores proporcionaban, según ellos, "el mismo veneficio al Estado que la de Orán y Zeuta, porque cada una respectivamente sugeta los puertos, calas y abrigos en la parte de la costa que les corresponde $(\ldots)^{*}(94)$. 
Los presidios rifeños permitían establecer un control marítimo que, en otras épocas de dominio naval español, no los hacía tan imprescindibles. En el siglo XVIII. la posesión de estas plazas

es el medio menos gravoso al Real Herario, porque los gastos de la conquista se hacen de una vez para siempre, y. sólo queda el de una moderada guarnición para conservar el presidio, lo que es claramente menos costoso que el crecido contimuado gasto de mantener multitud de esquadras que nunca pueden hacer tan seguro y permanente el veneficio (...)" (95).

Fstos ingenicros consideraban oportuna, incluso, una hipotética conquista de otras plazas costeras musulmanas como Argel, Túnez y Trípoli para controlar completamente a los corsarios árabes. Pero limitándose a la realidad del momento, el mantenimiento de los tres presidios menores permitiría a las embarcaciones sumidas en un temporal o perseguidas por corsarios refugiarse en sus fondeaderos, tanto en tiempo de paz como de guerra.

Desde un punto de vista moral, la función "purgadora" de estas plazas para los desterrados era considerada como socialmente positiva, ya que "la separación de los malos es útil a la conservación de los buenos" (96). Y para la religión oficial de la Corona, con los presidios "se logra tener puertas abiertas para que algunos se paren a dexar sus horrores, abrazando al catholicismo (...): pero cerradas para que de aquella parte no venga sobre nuestras costas el daño del cautiverio (...)" (97).

En el caso de que se decidiera el abandono de los presidios menores, Pedro Lucuze y Pedro Martín Zermeño opinaban que, de las dos posibilidades ("absoluto" y "condicional"), la del abandono condicional (que era la contemplada desde la Secretaría de la Guerra y consistía en retirar la guarnición, familiares, presidiarios y artillería; demoler las plazas; e inutilizar los puertos): resultaba ser una operación muy arriesgada (98), y traería perjuicios notables a las costas desde Andalucía a Cataluña:

(...) Después que perdimos Orán, un pequeño múmero de corsarios que de alli se dejaron sentir en la costa de Granada precisó a los havitantes de algunos pueblos abiertos a solicitar abandonarlos para retirarse tierra dentro. ¡Qué sucederá 
desde Melilla, Peñón, Alhucemas y demás puertos intermedios, estando más inmediatos a aquella costa? (...) (99).

Además de las costas peninsulares, los presidios mayores de Orán y Ceuta sentirían un mayor acoso de las fuerzas navales y terrestres musulinanas.

Pedro Lucuze y Pedro Martín Zermeño no eran partidarios del abandono ni del desmantelamiento de los presidios. En este sentido mostraron su oposición tras reflexionar acerca de tal hipótesis. La operación de inutilizar sus puertos resultaría infructuosa desde el punto de vista material, puesto que, entre otras cosas, "el mecanismo de los fluidos es problemático", refiriéndose a las características naturales de los fondeaderos, adversas para lograr el éxito en caso de cegado de sus fondos (100).

Por lo que respecta a las fortificaciones, sobre todo en el Peñón de Vélez de la Gomera (próximo a la costa) y Melilla, su demolición sería demasiado evidente a los vecinos beréberes, lo cual comportaría graves problemas en las labores de desmantelamiento y en la evacuación de la artillería y del personal. Por otro lado, el mantenimiento tampoco resultaba eficaz en las condiciones existentes en el momento de hacer el informe, ya que "las reducidas guarniciones (producto de la nueva planta de 1746) no pueden obrar como antes, ni aun hacer el regular servicio dentro de las plazas (...)" (101). Es por ello que Pedro Lucuze y Pedro Martín Zermeño solicitaban que fuera aumentado el presupuesto destinado a las tres plazas, o, de lo contrario, "habremos perdido toda la costa de Africa desde Orán a Zeuta y nos hallaremos en las antiguas calamidades y miserias (...)" (102): por lo tanto veían prioritario "se aplique luego el remedio de restituirles a su pie antiguo, dotándoles de competentes guarnición y embarcaciones, en que consiste principalmente su utilidad (...)" (103).

En caso de que fuera descartada la conservación de los tres presidios menores, los dos ingenieros proponían un destino alternativo para esos fondos. En tiempo de paz, senalaban la posibilidad de un tratado de comercio con los reinos musulmanes rifeños, "que tal vez podría convenir para tener libre nuestra navegación sin recelo de presas y cautiverios", en unos términos similares al pactado por aquéllos y Francia. Esta hipótesis diplomática y comercial, sin más argumentos, era calificada por Pedro Lucuze y Pedro Martín Zermeño como materia "distante de la qüestión" 
(104). Durante una tregua o un enfrentamiento bélico, el papel de los presidios resultaría imprescindible y no habría un sustitutivo que lograse alcanzar los objetivos expresados.

El refuerzo de los tres presidios se llevaría a cabo, según los ingenieros, mediante dos soluciones:

1. "(...) destinar a este efecto un cuerpo como los batallones de Marina, con cuya disposición la tropa se hará más natural y más útil por mar y tierra, no deviendo variar destino, exercicio ni otra disciplina que la conveniente a estas plazas (...)", prefiriendo que estos efectivos fuesen de guarnición fija, con lo que "se lograba el tener en los hijos y descendientes reclutas de la mejor calidad para hazer los presidios más respetables de los infieles (...). y de este modo se excusaría la molestia de tropa en guarniciones extraordinarias (...)" (105).

2. “(...) para veneficio del comercio y seguridad de nuestra frontera nada hay más preciso que guarnecer la costa de Africa con embarcaciones de corso, y toda la España con un competente número de guardacostas contra los piratas que vengan a infestarla desde Argel y demás puertos que hemos perdido (...)" (106). La función de los jabeques habilitados a tal efecto sería tener límpio el mar de corsarios, escoltar las embarcaciones de transporte y conducir diversos géneros desde Málaga, favoreciendo el comercio marítimo y la tranquilidad de las costas.

En definitiva, Pedro Lucuze y Pedro Martín Zermeño apoyaban las ideas básicas del informe elaborado por Miguel de Monsalve a propósito de la conservación de los tres presidios menores (107).

El marqués de la Mina, con el memorial de ambos ingenieros en la mano, no apoyó completamente las ideas de aquéllos. puesto que el Capitán General de Cataluña consideraba favorable el abandono de Melilla (108), convencido "no sólo por la fuerza que me hace lo representado por Don Phelipe Cavallero y los que le acompañan, sino por la voz común que siempre he oído de su gasto, de su inutilidad y inconvenientes para la deserción, el clamor y disgusto de la tropa (...), y por fin el grito unánime de ser unos puestos perjudiciales y peligrosos (..." (109).

El marqués de la Mina coincidía, grosso modo, con la idea de los ingenieros Juan Martín Zermeño y Antonio Gaver, aunque apoyaba 
resueltamente el nucvo proyecto de guarnición propuesto por Pedro Lucuze y Pedro Martín Zermeño, lo que posibilitaba el refuerzo de la línea costera estratégica Ceuta-Peñón-Alhucemas-Orán. El criterio del Capitán General de Cataluña, en la línea de pensamiento habitual en la época respecto de los reinos beréberes (110), no consideraba excesivamente rentable el mantenimiento de los presidios menores, sobre todo en una hipotética proyección futura de la Corona hispana en el Magreb:

(...) Muy remota, si no imposible, en la vista más perspicaz o el discurso que más prevea lo futuro, es la esperanza de bolver a las antiguas conquistas, ni que convenga emplear la sangre y los tesoros en hacerlas, porque jamás pudiéramos internarnos, por ser país donde sólo se posee lo que se pisa, porque son gente infiel para el trato y el comercio, y porque no presentan objeto digno a la gloria ni al interés, por lo qual no se descubre razón de Eslado que lo promueva (...).

No descubro, por fin, ventaja positiva en nada, sea christiana, militar ni politica, y muchas negativas y evidentes que influyen a la destrucción de los tres presidios; pero con la desgracia inevitable de no poderse practicar en los dos del Peñón y Aluzemas, que entiendo se deben conservar, como un mal preciso o como la llaga que no se cierra por recelo de que el humor decline a parte más noble (...) (111).

El expediente abierto tras la Real Orden de 23 de julio de 1763 sufrió un nuevo paréntesis durante el ministerio de Juan Cregorio Muniaín al frente de la Secretaría de la Guerra en el que no se tomó ninguna decisión al respecto de la suerte de los presidios menores. En 1772 aparecían nuevos datos que manifestaban la continuidad de la preocupación en torno a estas plazas, especialmente sobre el Peñón de Vélez de la Gomera (112). Con la llegada al Ministerio y al Consejo de Estado del conde de Ricla se dinamizó de nuevo la polémica. En esta ocasión, el 13 de julio de 1773 el ingeniero Juan Cavallero era instado a realizar un reconocimiento de los tres presidios menores junto al Ingeniero en Segundo Ricardo Aylmer, 
sobre si era conveniente su conservación o su abandono. El resultado de la observación se decantaba por el mantenimiento, considerando que

(...) si se abandonan los presidios dejando enteramente su posesión al despótico dominio de los moros resultará que, estando libres del continuo obstáculo que les causan estas plazas, establecerian en ellas considerables poblaciones mediante la buena proporción que les ofrece la fertilidad de sus terrenos, particularmente en Melilla y Alhucemas, de manera que con la muchedumbre de frutos y ganados de que abundan, adquiririan embarcaciones con las quales hera regular infestassen nuestros mares, sorpreendiendo estas costas y aun las de los reinos de Valencia, Murcia y Andalucía, privando en parte la nabegación y comercio de las muchas embarcaciones que continuamente pasan al occeano (...); ni del aumento de nuestras esquadras, ni del establecimiento de otras baterías y torres en la costa podrá erigirse el beneficio que oy experimentamos con la conservación de los presidios, respecto que aquéllas contrarrestarían en parte el mayor número de corsarios (...) y con éstas se les impide tolalmente su establecimiento (...) (113).

El criterio conservacionista de Juan Cavallero y Ricardo Aylmer quedaba bien patente en el extenso informe particular sobre los tres presidios menores (114). De ellos, parecía evidente que el Peñón de Vélez de la Gomera era la plaza con mayor capacidad estratégica, por lo cual fue propuesto por Juan Cavallero un plan de mejora de sus fortificaciones y fondeaderos, ante el riesgo de un sitio por los beréberes (115., De hecho. este asedio se llevó a cabo un par de meses después del breve proyecto de Juan Cavallero, entre el 3 de febrero y el 18 de marzo de 1775. En el período transcurrido durante estos enfrentamientos bélicos hispano-marroquíes y la fracasada expedición española contra $\Lambda$ rgel fue paralizada nuevamente toda iniciativa administrativa destimada a resolver el problema planteado por los presidios menores (116).

Desde la conclusión de las hostilidades y el inicio de la guerra contra Inglaterra en 1779 se produjeron nuevos intentos de retomar la cuestión. Según un Discurso anónimo redactado en 1777, el envío de un 
destacamento de minadores a Melilla reavivó la controversia sobre el porvenir de los presidios. La función de estos minadores iba a ser, en principio, la construcción de nuevas minas y defensas exteriores, aunque el rumor extendido hablaba de que su labor sería minar y volar las plazas de Melilla, Peñón de Vélez de la Gomera y Alhucemas. La opinión manifestada por los detractores del abandono presagiaba un desenlace no muy lejano a favor del desmantelamiento:

(...) como los dos Zermeños y el Veedor de Málaga, que opinaron por la conservación de estos presidios, faltan oy, tememos se aproveche de esta ausencia de Don Pedro Zermeño el partido que opina por la demolición para inclinar a ella la voluntad de nuestro Soverano (...) (117).

Esta disquisición anónima basaba sus argumentos en pro de la conservación sobre unos criterios económicos: posibilidad de obtener maderas para la construcción (únicos montes aprovechables desde Mogador a Túnez); mantenimiento de un relativo protagonismo frente a la rivalidad de las potencias marítimas extranjeras en el comercio con América (118)... cia y Andalucía)

Al ser las provincias mediterráneas (Cataluña, Valencia, Mur-

las que más contribuyen al Real Erario, parece muy conforme a la equidad de S. M. las ayude y protexa en el comercio de América, para que libres del temor de corsarios (tanto por el auxilio de los presidios como por la vigilancia de nuestras esquadras) puedan conducir con seguridad hasta Cádiz sus mercancías en bastimentos nacionales para entrar en parte de estas ganancias, y que no las sorvan todas las provincias que menos o nada contribuyen (...) (119).

El interés de estos presidios repercutiría indirectamente en el aumento del comercio español con las Indias, "para que no se lleven los estrangeros las producciones y metales de nuestras Américas, para que tengan pronta salida nuestras manufacturas, y para que la Marina Real tenga buques y marinos de que hechar mano en las ocasiones de guerra $(\ldots)^{m} ; y$ 
que, en definitiva, "quán unida está la felicidad del Estado al comercio, fábricas y navegación protegida, que faltando un eslabón a esta cadena se debilita el Estado y con él el Erario, que es el tema de la guerra (...)" (120).

Estos razonamientos económicos que demostraban la tendencia evolutiva de un mercantilismo favorecido por la explotación indiscriminada de los recursos naturales americanos hacia un incipiente capitalismo industrial y comercial, parece que fueron determinantes a la hora de decantarse la Corona por el mantenimiento y el fortalecimiento de los tres presidios menores. Si bien los argumentos militares no dejaron de tener validez, los motivos de índole económica fueron primando progresivamente, y las características estratégicas directas e indirectas de las plazas rifeñas iban creciendo con el desarrollo de las necesidades surgidas del sistema económico español y de los estados europeos.

En 1810, el ingeniero Antonio Samper elaboraba un interesante informe donde exponía sus opiniones a partir del memorial de Vicente Baussá sobre la conservación de los tres presidios menores. En él apoyaba la propuesta de activar el comercio con los beréberes para facilitar el aprovisionamiento de víveres y el mantenimiento general de las guarniciones destinadas en esas plazas rifeñas:

\section{(...) propone para su conservación el medio de} comprar a los moros los víveres y agua necesaria para la subsistencia de la guarnición y habitantes con las precauciones y formalidades que exige (...); es utilisimo en todos los sentidos siempre que se lograse un convenio para llevarlo a efecto, así por lo respectivo a la economía que deberá resultar en el ahorro de fletes, sueldos de empleados y almacenes, como por la seguridad de tenerlos provistos en todo tiempo, to que es muy. contingente (...). Acaso fuera un medio más eficaz, seguro $y$ permanente el abrir con los marruecos y argelinos un comercio franco con entera libertad de comprar y vender en sus puertos, $y$ recíprocamente ellos en los nuestros, todo género de frutas $y$ mercancías sin escepción alguna, según se praclica con las demás naciones amigas, quitando las trabas de las exclusiones particulares que dan lugar a que el interés personal se ante- 
ponga al bien general del Estado por las especulaciones más viciosas (...) (121).

A pesar de estas ideas de tipo comercial, el fin principal de los presidios menores seguía siendo táctico, ya que "nunca se pensó fomentar en la costa de Africa colonias civiles para la agricutura, fábricas, artes ni comercio de ninguna especie., y sí sólo apoderarse de sus puntos puramente militares $(\ldots) "(122)$.

La polémica desarrollada durante todo el siglo XVIII fue zanjada finalmente con la conservación de los tres presidios menores, que, junto a los mayores de Orán y Ceuta, permitían alcanzar los objetivos que. la monarquía española había deseado mantener en todo momento:

\section{(...) Nada más inoportumo y menos a propósito en el} día que el tal abandono. La nación agitada con la injusta guerra (de la Independencia) con que la la oprime un hombre (Napoleón Bonaparte) indigno de existir sobre la faz de la tierra, necesita más que nunca ostentar firmeza, energía, constancia y. poder; y fuera una debilidad y degradación del valor que la caracteriza, al paso que aumentaria el orgullo de un tal enemigo, viéndola desprender de unas posesiones que ya no podia sostener, de unas posesiones adquiridas a cosia de tantos afanes, tantos sacrificios y tanta sangre; $y$, finalmente, de unas posesiones que colmaron de gloria a nuestros grandes monarcas y de honor a las armas de la nación. Y acaso pudiera ser desagradable que a la venida del Rey N.S. (Fermando VII) a España enconlrase desmembrado un dominio que nos dexó entero (...) (123).

Junto a los tradicionales argumentos históricos para conservar los presidios menores (garantización de la seguridad de las costas españolas, control de los corsarios marroquíes, temor a la reorganización del corso musulmán...) y a las razones de cariz económico y comercial, se unían claramente las motivaciones tendentes a ofrecer una imagen de prestigio $y$ poderío de la monarquía hispana, dentro de la mentalidad colonial-estratégica que también otros países europeos mostraron hasta bien entrado el siglo XX y que todavía perdura en la actualidad. 
1. Esar pomencia ha sislo elaborada búsicarmente a partir de la doeumenatión existrule en ol Serricio Ilistórico Militar ale Mardrid (SIIM). comeremamente en su Catálogo Cencral de Documentos (C(;D)). Las referencias documenales apareren en el cexto de forma alureviada.

Parte del material gráfico corresponde a la Cartuteca llistórica (CH) del mistmo archivo.

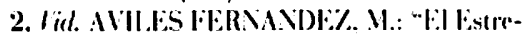
rlo de (;ibraltar en la Edad Modorma”. an Leteas del I/ Congreso Internacional "lal listrecho de Gibvellar" (Ceuta. noviembre de 1900). en prensa.

3. Para tener una visión elara de la ulicarión de lalos presidios en el conjumengengrálico del área del listrecho de Cibraltar, rid. ligg. 1.

4. Iid. Dictamen de Don Mignel de Monsalre. leedor de .Hoilaga, sobre la utilidad de conservar

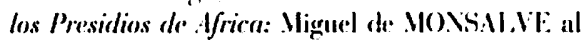
marques de ES(O) II AC:HL: Málaga. 29 de noviembre de 1763. (SIIM. CCOD. 89)1. +-5-6-6). liols. $20-2 v$.)

5. Iäl. Diclamen del Eirmo. St: Marqunes do la Minu sobre la conservación de los dos presidiess de Africo, Peñón . Aluzemas, y demolición de el de belilla e'n 20 de Abril de 76.5: marqués de la III II al marqués de ESOL II.ACIIli: Barrelona. 2 ? do aluril do 1765. (SHIM. (:(D). 89:3. t-5-6)-8. fol. 5v.)

6. Vïl. lical Codula de S.M. Ielipe I: disponiendo la provisión de viveres de los tres presidios de Mrlilla. Peñón y Alhucemas en I). Predro de Astreareno: Folipe $V$; San Ildefonso, 10 ile agosio de 17:26. (Biblinuteca Vacional, Madrid.)

7. Vïl. Worizias generules sobm hes Presidios de Africa que son agregados a rel commondo de la

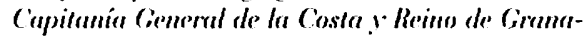
da: Pedro (o) SLliox. s.d.: Málaga, 25 de

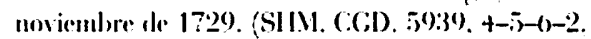
[ol. 1r.)

8. Jid. ms.cil. en nota ?. lol. Iv.

9. Jïl. ms.cit en nota ?. fol. 2r.

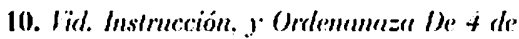
Julio do 17/S. Parre los Ingenireres, y alres personas, dividida en dos partes. En la primern se tratu de la formacion de Mapas, o Carters Cieogrufuces de Provincias. con obserraciomes, y molas sobre los hios que se pudieren hacer naregables. Azequias porr Wolinos, Batames. y. Riegos, y otras dirersas diligencias, dirigidas al benefirio unirersal de los Pueblos: y assimismo el reconocimicnto. y formencion de Planos, y relaciones de Plezas, Purrlos de War, Bahias, y Coslas; y de les repe-

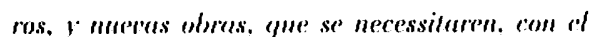
lamleo de su rosip. En la secrunda se expressan less reconocimiantos. Ianteros, y formmlidales con que

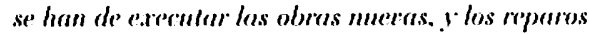
que fureren precrisoss an less Fortificariones. Ilmo-

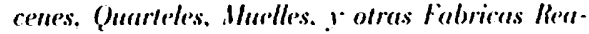
les. I sobre la conservacion de las Plazas, y Pruertos de Mar. s.l., s.eil.. s.al.

11. Iïl. ms. ril. en mota ?. fols. 2-v-3r.

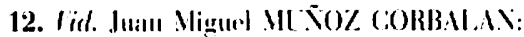
la labor professomel so los ingenioros milituress "burboinicos" de flameles a España ( $1691-17 / 5)$.

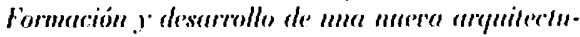
ra modernu an ('alalumin (tesis doctoral). Banrelona. Iniversidad de: Barrelonal-Servivio de Publicaciones. 1000. pigs. 303-40.5. lide lambien

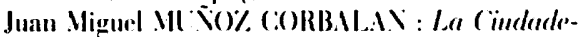
la de Burcelena (ITI.5-I:IS). Barcelona. s. el.

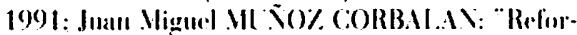

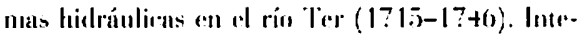

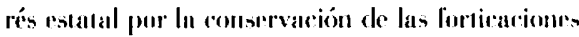
de Ceroma", en Areses del IIl Congreso Espormol do

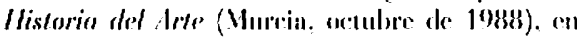
prensa: Juan Migual 111 50\% (COBALA.): "I.os cuarteles de Barcolona clurante el reinado ale Felipe $\mathrm{V}$. L na responsabilidar ronstreativa compartida". an Ilomenaje a Amlonio Bomel Correa. Madrid. L miversidarl complutense. en prensil: y

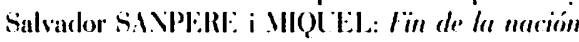

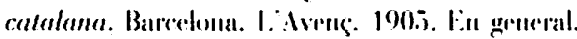

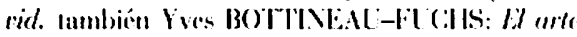

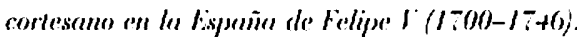
Madrid. Fumdarion l niversiaria lispañola. 1084.

13. Iid. Pluno de la Plaza del Pejion: Juau

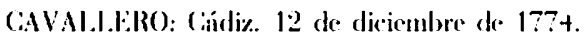
(SII). (:(i). $) 11 .+-5-(1-11)$,

14. Jid. Descriprion del estado achal de la Plaza del Penion de lislez de la Comerne con al Diario del Sivio que ol Eimperador de . Harruecos

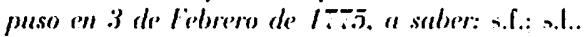

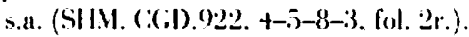

15. "(..) I als culermedades que mís ale ordinario alligen es excorbuto y falta de visa on

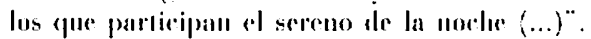

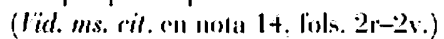

16. Jïl. ms. rit. ell nola 1t. fol. 2v.

17. Jiel. ms. rit. ell nola 1t. fol. 2v.

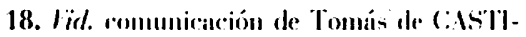

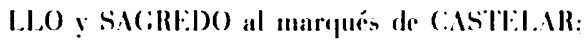
Peñón de Velez de la comera. 20 de abril de 1721. (SIIM. (; (;). 59)16. +-5-7-2. fol. 8r.)

19. Iirl. ms.ril. wl nota 18. fols. 8r-8s: 


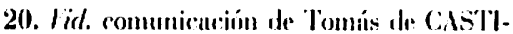

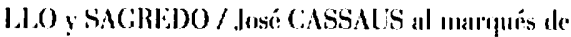
CASTVI AR: Peñón de Vólez de la Cimmera. 28 de

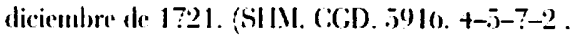
fols. $11 \mathrm{r}-11 \mathrm{v}$ )

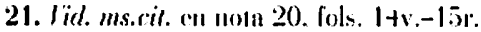

22. lial. commuicatión del martumes de (AS-

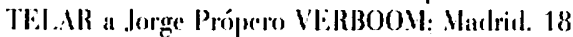
le febrero de 1722. (SIIM. (:(i). 5016. t-5-7-2. fol. 1r.)

23. lid. commuicarión s.f. (lorege Própero

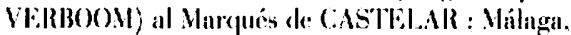
$1+$ de fobrero de 1722. (SIIH. (i) (;) 5916. t-i-?-2. (ol. .3r.)

24. Jïl. ms.cil. en mola 223. fol, 3r.

2i). lidel. Breve Provecto de la Plaza del Penón do Vélez de la Ciomera, Iras su misma dominarion dessi: Tomán de (AATII.I.O y SACill:DO. s.d.: s.l. s.a. (SIIM.(III), j(9)16, t-5)-7-2. tols. $5 x-5 x$.)

26. I a narración de como lograron los beréberso apropiarse del Próno es hario jocosa y simplista.

“(...) Por tradición se sabe cue un Cinsmador vicioso tenia demasiado comercio y trato con los morns: y Ross por eomplacerle y lisongararle el gusto. le labalian mugretes para que se collase y divirliese. roul ruyo motivo se imtrodujo copria de ellos, tue repentinamente se hicieron dueñus do la puerta principal y. por comsiguientere de la plaza (....).”.

(liil. Descripción de la Plaza dol Periem de liblez de la fiomera enl la cosla de diriva. en que. se expomen las cosos más nolables pare el ronocimienlo de aste Presidio, seguin sn estado an. 30 de Junio de 1732: s.l.: Penion de leloz de la (iomera. 30 de junio de 17:32) (Silll. (c(i). 5978. $+-\bar{z}-7-8$. fol. $+\mathrm{r}$.)

27. lïl. ms, cit. an nota 26. fol. :3:3r.

28. Iid. Instruccioin a el Jleavele Juan de Molina, freha en al Lscorial a postrero ale Junio

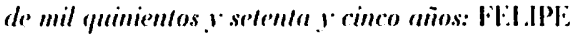
II: lil liscorial. 30 de junio de 1575 . (rirl. ms. cil. en now 20. liols. 341-333\%.)

29. Iid. ms. cit. me nola 20, fol 31 .

30. lïl.ms. cil. en mola 20. fol. 3:2r.

31. Ï̈l.ms .cil. en nola 20. fol. 33:3s:

32. Viel. Reflexiones rorrespondiontes a la Plaze del Peinón a fin de disponerla parn su mejor

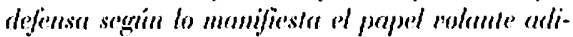
cionado al plano que ho acompaña lown (:IVA1.I.t.RO. s.d.: Cárliz. 12 de diciemlire de 1??t.

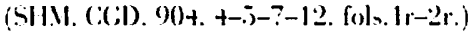

33. Plamo de la Plaza de Allucemosi sif. Allusemas. 2 de marzo de 1775. (SIIM. (i) 911. +-5-(i-11)

34. Lïl. Reconocimiento do la Plaza de Ihuremos: Inis de LRBINI / Inan CAVII.I.LRO / Ricarcedo dYL.ML:R: Allucemas. $21 \mathrm{de}$ juliu

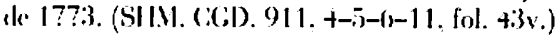

35. Sobre Melilla y la hisasria dr sus lortili-

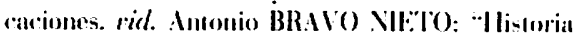
de las fortificacione de Melilla". en IMan espercial de Rehabilitación de los Cualro recintos fortifiendos de Melillr. Melilla. Aymumirnto de Melilla.

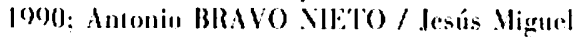

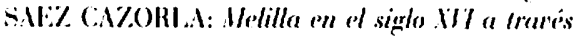
de sus fortificariones. Nelilla. Nimmamiento de

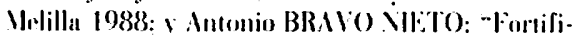

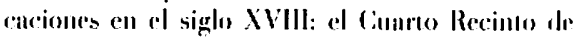

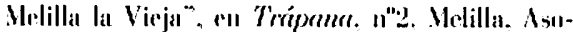
ciarrión de listurlios Melillenses. 1988. pígs. 20-t2. De este mistmo antor. virl. también sul tesis de licenciatura en proceso de claboración tionlada ligenieros y fartifiraciones en la Plaza do Mrlilla: sighos $17 \%$ a irlll.

36. Iid. Aproulación que romprehende la

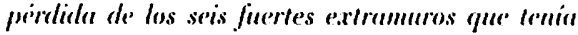
psfa Maza de Melilla en su campana y las obros mis prorticulares que se han hertho de mil seiscienlos y cingüenla y' seis a esta pante: y estado presente de las embaracriones, osprital y rotica: Virnlís V.170L E\%: Melilla. 28 dr juliu de 172.2: Des-

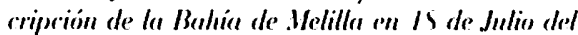
año de 1720 de resulla de aberla recomocido rel

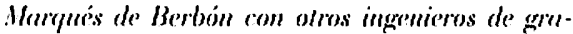
duación y la mayor repulación: s.l.: s.I..

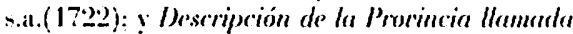
Alcalaua, y Relarion de la Ginte de Armas que pueden arudir do este Provincien on campo del Moro delemere la Maza de Melilla y en quainto

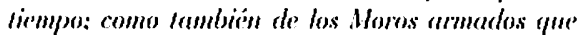
pueden acudir de la Prorincian de Onirioma ."

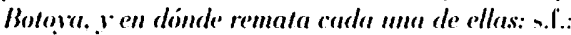

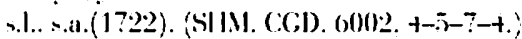

37. lïl. armunicación de dorge Próspere Vl:RBBOOM a laime SIC.RE: A lome de la gallera Somba Terese, delante de Alhuermas. 3 do juliu do

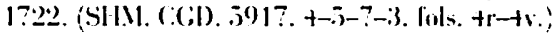

38. Iidl. Rrelazion de torlas las zirrumstomzins. quer ronduzen a la ajustado intelige'nzia de le que

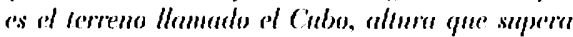

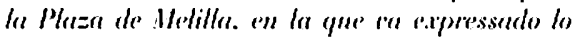
qure los infieles puesden exerular para imbadir al imlento de forlificarla . las preromziones que se 
dererain tomar a fin de poseherla con el menor riesgo: s.f.(Juan de l.AFliRRILRli): s.l..

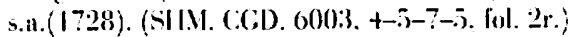

39. lirl. ms.rit. en mota 38. fols. iv-or.

40. Mloma de GLEVARA VASCONSlitos ologiaba al ingeniero en estos tíminos:

-(...) en corlos los Malbijos releridos se ha señalado murelo el selo de Dou Juan Marlin \%ermeño. esponendose al mavor riesto y llevando sobere su cuidaclo el buen orden yore all estas precisas fachas devia conservar lanla gente. y lo

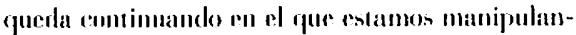
do en el Cubo. que espero se limalise on la misma Pelicidad yue codos. por lo enal y pror la bivesa y atsiduidad con yue se sarrifica en todas las oluas

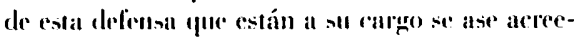
dor de la grmeia y protección de V. L. para que le andelante rol el grado de Ingenioro en segumdo. que aseguro a $V$. V. lo merese birn (...)".

biid. rommonicación de Alomso do (iL EVARA VASCONSELCOS a Jorge Própero VERBOON: Melilla. 2t de felorero de 17:20). (SIIII. (:(;D). $600+$ + $+-5-7-6$. fol. 8r.)

41. Virl. communación de Juan Marín ZIER-

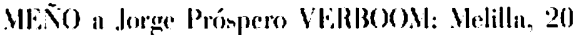

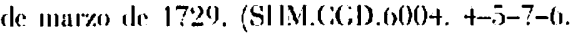
fiol. 1.5v.)

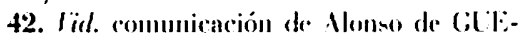
VARA VASCONStIOS a Jorere Próspero VERBOON: Melilla. 21 de julio de 17:29). (SIIM. (:(;). $600+$. +-i)-7-6, fols. $21 \mathrm{r}-2 \cdot 2 \mathrm{v}$.)

43. I Irl. commuicación do Junn Martín ZliR-

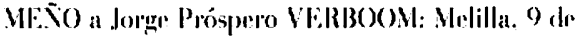
agusto de 17:31. (SIIMI. (COI). (1105) +-5-7-7. fols. $+v-5)$.

44. Iid. romunicacion de luan dudrés del TOSSO a Jorge Próspero VV:RB()( ).M: Melilla. O de ahril de 1731. (SIIM.(:(:D).ol)o.j. +-5-7-7. lols. $41 v-+2$ r.)

45. Vid. enmunicacion de Pedro coYsl: VOX a Jose PNTITO (copia): Sun Roupue. $1+$ de septiemlire de 1731. (SIIM. (:Ci). 6005). $+-5-7-7$. fols. $10 \mathrm{~s}-11 \mathrm{r}$.)

46. Iirl. ms.rit. en nota t. fol. ov.

47. Jid. enmuniración de Juan Marnim ZFiRMEXO al marpues de la ENSLNADA (eopia): Baredoun. 11 ile enero de 17+\%. (Sillil. (c) 889. +-5-0-t. fol. 16r.)

48. Iid. ms.cil. en nola t5. fol. lov.

49. Iitl. Extracto historiro-político con roflexiones importantes para el acirrto que pide el dickamen sobre los cinco presidies yme.t. .l. pose'

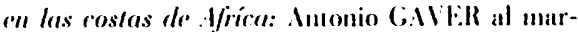

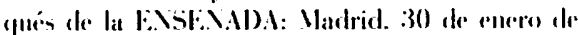

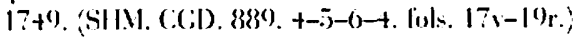

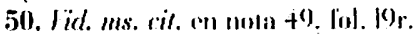

Respectu ilo (ilmaltar. el brese amailinis de sus caracteristicas eslatiogicas realizado por los

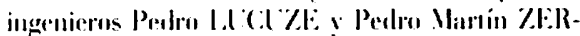
III: $\mathrm{X}()$ era mur significanivo:

....) lis deseracia connum no estimar el hien husta cue se padoce el mall sobran lus exemplares en la hisforia y uinguto más pallento que de (iibraltar. No comorimos hien sll urilidad quando

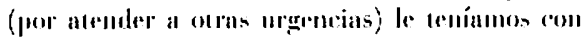
vilo 80 hombres. sill artillería ni municionen necesarian a su deferna: y despues de perdielo recomoremos con semtimiento at importantia (...)*

(Jid. Discarso de less Brigadieres Don Perlro de Lancer y. Don Pedro Martín Zermeno sobre

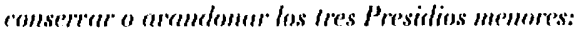

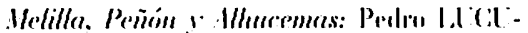

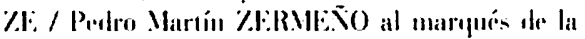
MIIX: Barcelona. + de marzo de 176.i. (SIIII. (:(:D. 9(19. +-5)-6-(1. fols. 37v-38r.)

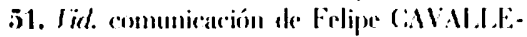

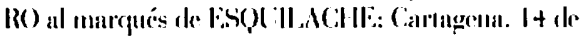

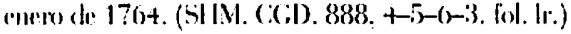

52. Vid. roumunimarión s.f. a la Junla do Gencrales: Mandrid. 15 de abril de 1700. (Silll.

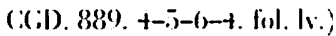

53. Jid. ms.rit. ell mona 52. fol. ir.

54. Iïl. Instruction de lo que deberei obser-

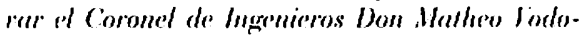
pirh en al recomorimiente de los tres pressidios

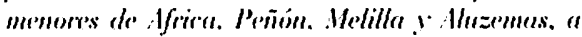
curar comision le destina S. M. Heramte a su orden al Theniende (omonel de Ingenieros Don Segismundo Font: Ricardo WVII.I. a Malheo

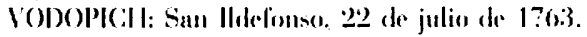

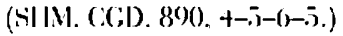

5j. Vid. Helureion y Descripcion indiridual del Presidio . Plaza de Melilla (...): Maneo VODOPICIl. s.d.: Carlagena. 1t de enero de

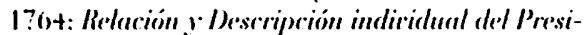
dio del Peñon de lílez de la Gomern (...): Malteo VODOPIC:H, s. al.; Cartagena. 1+ de anero de 176t: y Relacioin .) Mescripción indiridand del Presidio .r Plaza dr Allheremas (...): Mateo VODOPICH. s. I.: (anragena. $1+$ dre conero de 17(1+. SSl1M. (C) .888. +-5-7-10. 1. B y (:).

Existe una copta en forma de exiritelo que reproduce ínicancente los puntos 6 y 7 del informe. lis esta la que utilizaremos para nuestras 
trinscripeiones. (SIIM. (.CI). 8888, +-,i-()-3.)

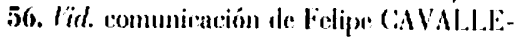
RO al marefués de ESOLII ACIII: (copia): (arragena. It de enero de 1?6t. (SIIII. (:(i), 888. +-5)-(1)-3. fol. 1r.)

57. lid. ms. ciit. en nola jo. fols. Ir-1s:

58. lide. ms. cit en uno jo, fols. Iv-2r.

59. Iirl. Presidio y Pllaza del Peñón de Vélez de la komera: s.f.: s.I.. s.a.. (SIIM. (C(B). 888. $+-5-(2-3.3$. Fol. 8r.)

61. lid. ms. cir. en nola 59. fol. 8v.

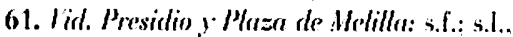
s.a.. (SIIM. CCD. 888. +-.j-6-3. fol. 1+r.)

62. Iid. ms. cit. ril nota 61. fol. 1tr.

63. Iid. ms. cil. moll nol. fol. 1ts.

64. Iidt. Resumen Cineral de Gesstos: Felipe: CAVIII IERO / Mateo VODOPICH / Segismumlo FONT / Pedro JlSTLNIANI (copin): (arlagena: 1t de encro de 1764. (SIIMI. C(C) 888. +-5-6)-3. fol. 1.5r.)

6.5. Iid. ms. cil. montat.

66. Iïl. ms. cil. en nota t, fol. 2ty.

67. Iirl. commuicanión s.f., s.ll.: s.l., s.a.. (SIIV. (C) 892. +-5-6-?. fol. 1r.)

68. liid. ms. cil. en nota t. fol. tr.

70. Iid. ms. cil. moln nota t. fol. 5v.

71. Vid. ms. cit. col nowa 6?. fol. |r.

72. liid. ibid..

73. liid. ibid.

74. Iidl. Reflecciones politicus y militares sobre la importante güestion controrertida de si combieme "la Reliavion y al Sstado comserwar o abandonar los tres Prossidios menores: s.l.. s.d.; s.l.. s.a. (SIII. CCD. 892. +-.5-6-?. fols. 201ry ss.)

75. Jirl. ms. cil. e'll mora ?t. fol. 20):

76. lidl. ibid.

77. Iial. ms. cril. "nll nula 7t, fol. $21 \mathrm{v}$.

78. lil autor de psta reflexiones se indignaha sarcástimamente por la opinión expresada por Felipe (:IVALIERO sobre que "el Todopoderoso contimuarí el milagro de la ceguedad" de los bereberes a la hora de mulrentarse a la Corona española. (Vidl. ms. cit. en nota 7t, fol . 22.2r.)

79. Iirl. ms. cit. con nota ? t. fols. 22v-23r.

80. Iidl. Resumen de las Reflexiones: s.f.. s.d.: s.l. s.n. (SIII. CCD. 89) 2. t-i)-(i)-7. fol. 31r.)

81. lid. Reflexiones: s.l., s.d.: s.l., s.a. (SIIV.c(;i).892, 4-5-6-7, lols. 26r-30v.)

82. Iïl. ms. cir. pu nota 81, fol. 26r.

83. Iïl. ms. cir. en nota 81. fols. 26r-20v.

84. Iidl. ms. cit. en nora 81. fol. $20 \mathrm{v}$.

85. Jid. Discurso (...), ms. cir. en nota 50).

86. Virl. "Parte primera yur comtiene resumidamente las razones fundamentales. asi generales como particulares para cl abandono de los tres Presidion. conducla para sul demolición . imbersión de su coste en oro cofuivalente más ítil. segím resullan do documentutus cyue presentan low yuatro ofiriales convenidos con liecha en (armagena a $1+$ de hesero de 1?64-" ('n Discurso (...) (ms. cit. en nota 30). fols. 2r-9r.

87. Iid. "Parte 2". Importancia de conservar less Presidion y pourerles solve el pire antigno según prueba Don Miguel de Monsallee". en Discurso (...) (ms. cit. in notn 50). fols. 9v-22v.

88. Iidl. "Parte tercera. Reflexiones politicas y militares solbre contservar o anandonar los tre. Pressidios memores, en Discurso (...) (ms. cil. col nota 50), fols. 22vinttr. fiol . 2.

89. Jirl. Biscurso (...) (ms. cil. en nota .jo)).

90. lial. ibidl. fol . 23r.

91. Pspaña poséa, según lus critrrios técuirus de la cipora, ruatero fromteras. do las cuales la rnfrentada al noree de Africa cra la más delicada:

"(...) la reue corresponde al norte es. por su muturaleza. la mús defendida. porque la Canlatria es ńrida. escéril, montañosa y distante de ser

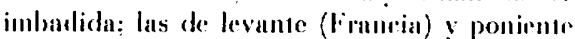
(Portugal) romrejeonclen a prímripres de nuestra religion. cuyas diferencias por razones de Estado se trominan con facilidad: pero las del mediodia mereen otras alenciones, poreue las costas de Aurlalucia, Granarda. Murria. Valencia y Cathaluiia sou las más apreciahles por sul fertilintad! comercio del Mediterraineo. y por tener a corta distancia la costa de Africa (......

(liid. ibid., fols. 23r-23v.)

92. Pedro I. ICUZli y Perlion Martín ZIilRMI: $\mathrm{NO}$ (laban "razones miliares acreditadas por la experiencia" para alimar que "prara dominar una costa of frontera. hasta ocupar los puestos más principales y on distancias competentes para que st guarnición pueda sugetar a los menores immediatos (...)". (Vid. ibid., fol. 2(ov.)

93. Iïl. ibid., fols. 2+v-2.5r.

94. Viel. ilids.. fol. 2.5 r.

95. Vidd. ibirl. linl. 2or.

96. Vidl. ibirl., linl. 27v.

97. Para alcanzar estos objetivos se había destinado a los presinlios caudales de "Cruzada. Subsidio y Escusado". (Vid. ibid.. fol. 28r.)

98. iidl. ibidl. fol. 29 r. 
99. Fid. ibid., lol. 30r.

100. Vid. ibid., fol. 333r.

101. Vid. ibid., lol. 38v.

102. Vid. ibirl, fol. 391 .

103. Vial. ibid, fol. $39 \mathrm{~s}$.

104. Firl. ibirl. fol. +0 r.

105. Iid. Cols. $41 v-+2 r$.

106. lidl. lol. t'2v.

107. Jîl. "Resumen y Dirtanmo". m Discumso (...) ( $m$ s cil. en nola 50 ). fols. $+4-+5 \mathrm{r}$.

108. Vid. Dichanen del Exmo. Sr: Marqués de la Mina sobre la consernación de los dos presidios de Africa, Peñon y Alnzemess, y demolición de el de Melilla en 27 de abril de 176.5: marpués de

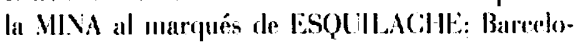
na. 27 de abril de 1765. (SIII. (COD). 893, $4-5-6-8)$.

109. Iid. ms.cil. en nota 108. lobls. 2v-3r.

110. Cuvos habilantes eran calilionelos de gente muy perezosa y lústica quo no cuidan de Cabricar casas para su albergue: sólu so contentan de abitar unas malas chozas hechas ale juncos. que abandontan cuando se las antoja. Que mas vezes avian la monaña y otras al llano (....). (Iid. Descripción de las Mazas de Melilla. Alluzemas y Peñón de Vélez de la Gomerr. Ilamorla Presidios de Africa: s.l., s.d.: s.l., s.a.[1790]). (SHM, C.CD. 939. +-j-8-6. fol. 12r.)

111. Vid. ms.cit. en nota 108. lonk. +v-5re.

112. Iid. Relación de has remlajas y defonsar que ofiece la plaza del Peñón como rasimismo el numero de abilatomes, almahasenes. quarleles y. olros edificios, con una disuribución grogrifica al pris que cubre y el liempo en que fire conquis/nda: s.f.(a partir de unas rellexiones del lngeniero Ayudame Jacinto ROS). s.d.: s.l.. s.a.(10) de mayo de 1772). (SHM. CGI) 9(13. +-5-7-11.)

113. Fid. comunicación de luan CAVAI.l.l:RO a Luis de LRIBINA: Málaga, 11 de agosto de 1773. (SIIM. CCD. 910, +-5-6-10. fols. 1r-1v.)

114. Vid. informe de Juan CAVALISRO/ Ricardo AVI.MER a Luis de LRBINA: s.l.. julio-septiembre de 1773 (2+ de septimbre do 1773). (SHN. CGD. 911, +-5-0-11. fols. Ir-66ov y $68 \mathrm{v}-78 \mathrm{r}$.)

115. Vid. Refleriones correspondientes a la plazn del Peñon a fin de disponerla para su mejor defensa, segin lo manifiesta el papel volante adicionado al plano que to acompaña: Juan CAV AL.LlilzO, s.1.: Cádiz, 12 de diciembre de 1774. (SIHY. CCD. 911. +-5-6-11. Culs. $67 \mathrm{r}-68 \mathrm{r}$.)
116. Orass empresas relacionadas de alguna manera con las plazas liapanas en la costa rileña sufrieron el clecto ale la guerra. como fue la congelación del Gabinete de Macpuetas. (Vid. duan Vigued MUNOT CORBAI AN: "Lats matqueas de Coula y de la Bahía de Cásliz (1779). Proyectu de cartumafia en relieve para el conton del Estrecho". en Actas del // Congreso Internacional "SI Estrecho de Gibrallar" (Cenla. noviembre de 1990), m purnsa: Juan Miguel HI:ОOZ CORBAI.AV: "I.a Coleceión de Relieves de las Furtificaciones del Reino. Rssai d'organisation da Cabinet ro Pans-Reliefs en Esprgne pendann le rògne de Chartes III. "n Aches du "Collorme Scientifinur" Puridisciplinaire sur les Plans-Roliefs" (Paris. abril de 1000). en prensa: Juan Higuel MI SOZ CORB3ALAN: "I plastici e la difesa alel territorio sjagnolo al tempo di Carlo III. Fallimento re manrata assimilazione del mulello francess". en Alli dei Colloqui Internazionali "Castelli e Cillì Fortificale. Storiu-kerupero-laborizzazione". Lidine.

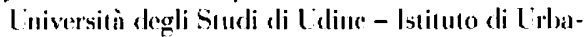
nistica e Pianilieazione, 1990. pígs. 1-t: y Juan Mignel VL NO\% CORBAL AN: "La Varquela de Cádiy (1777-1779)". all Artas de las formadas Vacionales sobre Wa lageniería Militar y la CalIura Artistica Española" (Cádiz. noviembre de 1989). en prensa.

Como ampliación de esta ponencia ney claboramelo el estuslio vimado Melilla versus Chafarinas: polímica en torno al desmantelamiento de Melilla bajo el reinado de Carlos HIF".

117. Iitl. Discurso sobre si rombienr ronserber o demoler los Presidios menores. lño de tr.t. s.l., s.d.: s.l., s.a.(1777). (SIIM. (C;D. 920. t-5-0-1:3. lol. 1r.)

118. La preponderancia de países como Inglatrern. Francia, I Colanda o Rusia quedaba explicitada por el autor de la memoria. Este culpalsa indirectamente a la Compañía de Caracas y a sus representantes en la administración del Estanlo de ser los responsables de instigrar el ahanrlonn do los presidios mennes rileños:

*... (pnemos en eleno de la Monarquía un partido de gemes que opinarán por la destrucción de los puesidioss prefiriendu lon propios y parrienlares aumomos de su país al bien general de la mación. Essa será la Compañía de Caracas y el resto de las provineias del oceano, yue barian privativamente el comercio sle Américo. sin que catalanes. valencianos, murcianos $y$ andaluzes pordicsen mantener igual comereio; porque perdidos 
Psilos tres presidios nos inumelarian los tuoros con sus galeotas al Verliteríneo; y como el comescio es ol ave más tímida, o cesarium de lacerle los que abitan desde Rosas a Gibraltar; o havrian de lacerte con quadriplicados dispendios de armamentos, aumeno de tripulaciones y de seguros, o bien abandonar nuestras merenncíts a los cargadores extrangeros gue nos lass condugesen a duéri12a. De cualquicra manera logravan los de la Compuñía de Caracas redimirse dis los celos y rnidosos phisos que trae con los calulantes sobre aprovethar'se ćstos con Reales privilegrios do un perlazo de territorio immediato a Carncas que cenía abamdonaudo y ollbidaulo esta compañia (....)".

(Vid. ms.cil. en nola 117. Fols. 3r-4r).
Solner la constión del comercio mediucrúneos con Amirica, widl Inse Marín OLIVA Mli., CAR: E:I comercio colonial de Catalutia en la épocea de: Carlos III: del sistema de puerto únteo al comerercio libre. Aportaciones y debates": en Actes del Segon Congrés d'llistória Moderna de Cortalunya (Pediralbes. Rerista dWhistoria Moderma, uno Villi. 1988. 1" 8-1). prígs. +47-468.

119. Virl. ms. cil, bol nota 117. fol. +r.

120. litl ibid, fols $7 \mathrm{r}-\mathrm{Tr}$.

121. Ridl. bomtunieación de Antonio SA.YPleR, s.d. (copia): Isla de León. 1 rle abril de: 1810. (SI IMI. C(CD) 954, 4-5-60-14, fols. 11-1v.) 122. fid. ms. rit. en nota 121. Pols. $+1-4$. 123. Iid. ibid . fol. 5v. 